\title{
Cell Therapy: A Therapeutic Option for Multiple Sclerosis
}

Mohammad Reza Khojasteh", ${ }^{1,2}$ Seyed Ali Shariat Razavi, ${ }^{1,2}$, Aida Javadzadeh ${ }^{1,2}$, Ali Gorji ${ }^{1,3}$, Sajad Sahab Negah",4*

${ }^{1}$ Department of Neuroscience, Faculty of Medicine, Mashhad University of Medical Sciences, Mashhad, Iran

${ }^{2}$ Student Research Committee, Mashhad Branch, Islamic Azad University, Mashhad, Iran

${ }^{3}$ Epilepsy Research Center, Westfälische Wilhelms-Universität Münster, Münster, Germany

${ }^{4}$ Shefa Neuroscience Research Center, Khatam Alanbia Hospital, Tehran, Iran

\section{Received: 19 Dec 2017 \\ Article Info: \\ Revised: 28 Feb 2018 \\ Accepted: 5 Apr 2018}

\section{A BSTRACT}

Introduction: Multiple sclerosis (MS) is an autoimmune disease of the central nervous system (CNS) that can cause demyelination and axonal damage. There are different therapeutic approaches for MS, including administration of interferon- $\beta$, Glatiramer Acetate, Natalizumab, Fingolimod, and other immune-modulating agents. Currently approved MS treatments primarily decrease CNS inflammation. Noticeably, the unsolved challenge in the MS field is to advance neuroprotective and remyelinating approaches for the treatment of MS patients. Treatment strategies to prevent tissue damage and/or enhance remyelination and axonal regeneration are seriously needed. Conclusion: Recently application of stem cell therapy for MS therapy has created a lot of hopes to treat MS patients. Several studies have been shown that stem cell therapy has immunomodulatory and anti-inflammatory effects in brain tissue. In this review, we have explained the properties of different types of stem cells and their role in the treatment of MS.

*Corresponding Author: Sajad Sahab Negah

E-mail: sahabnegahs@mums.ac.ir 


\section{سلول درمانى: يك راهكار درمانى براى مالتيبٍل اسكلروز}

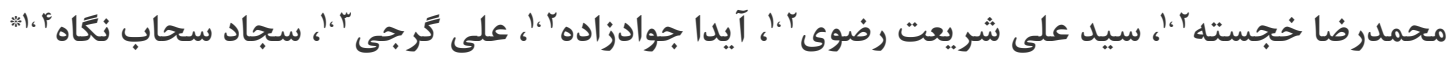

$$
\begin{aligned}
& \text { 'حروه علوم اعصاب، دانشكده يزشكى، دانشگاه علوم يزشكى مشهد، مشهد، ايران }
\end{aligned}
$$

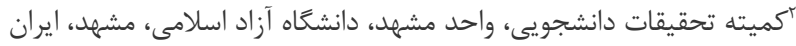

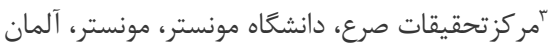

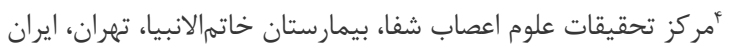

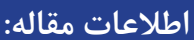

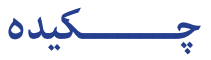

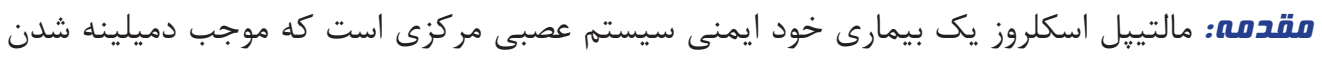

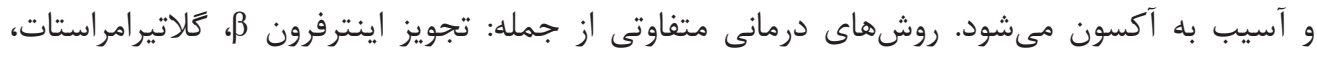

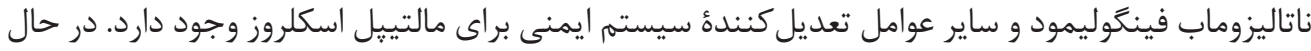

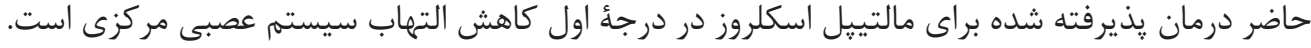

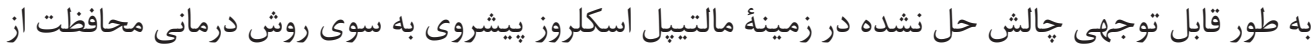

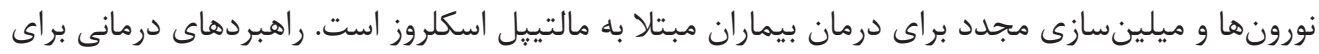

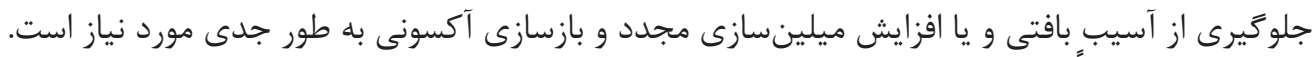

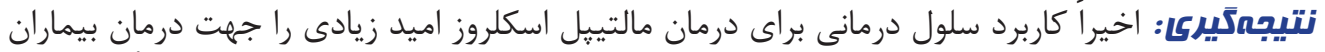

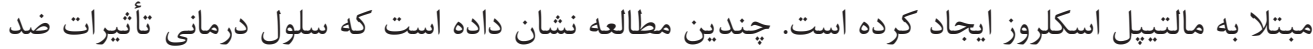

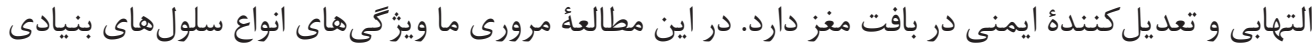
و نقش آنها در درمان مالتييل اسكلروز را توضيح دادئ دادهايم.

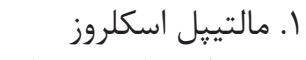

كليد وازهها:

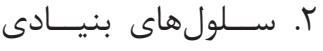

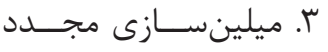
أ. مركـن 


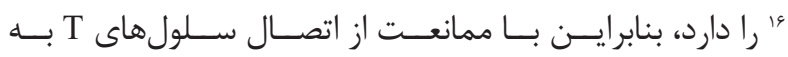

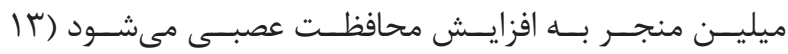

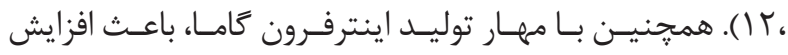

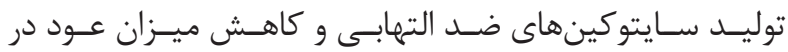

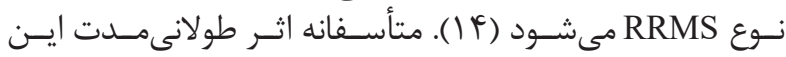

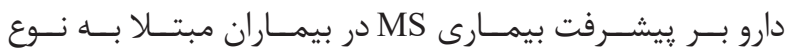

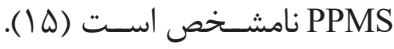

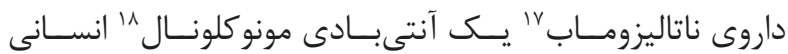

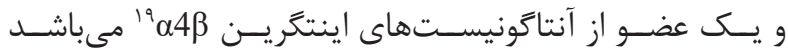

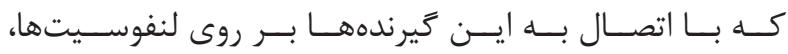

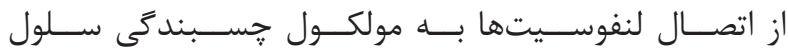

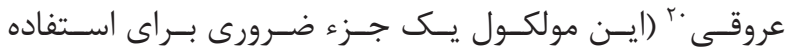

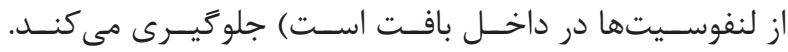

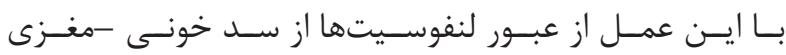
(BBB)

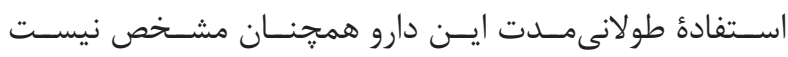

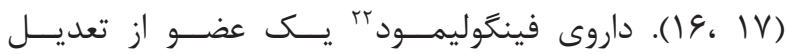

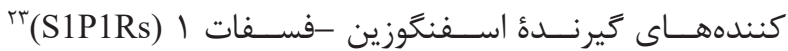

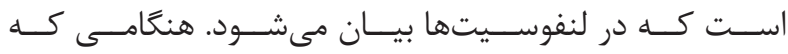

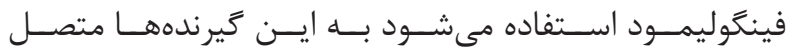

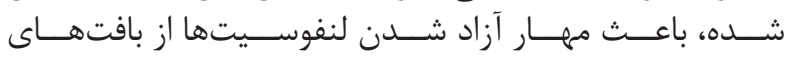

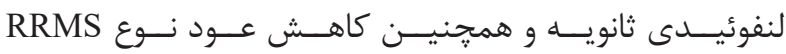

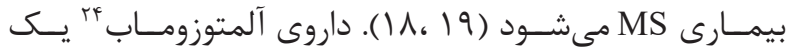

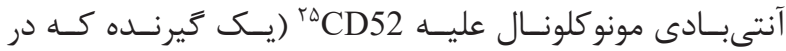

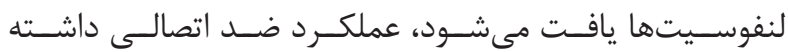

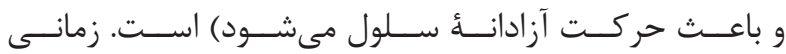

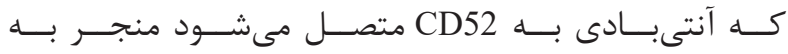

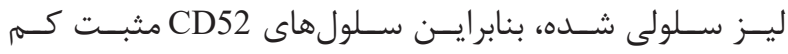

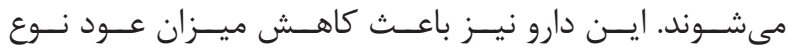

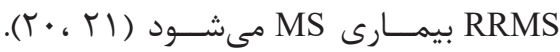

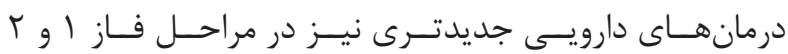

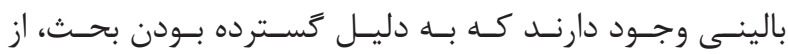

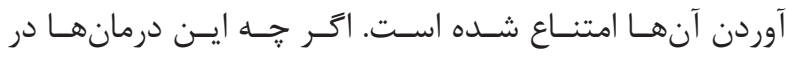

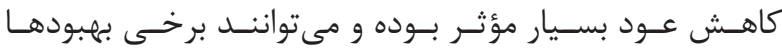

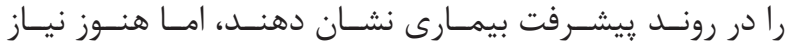

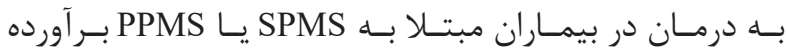

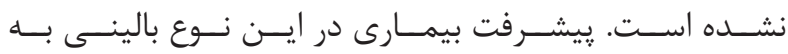

\footnotetext{
${ }^{1}$ Multiple sclerosis

${ }^{2}$ Oligodendrocyte

${ }^{3}$ Etiology

${ }^{4}$ Tumor necrosis factor

${ }^{5}$ Interferon- $\gamma$

${ }^{6}$ Relapsing-remitting multiple sclerosis

${ }^{7}$ Primary progressive multiple sclerosis

${ }^{8}$ Secondary progressive multiple sclerosis

${ }^{9}$ Progressive-relapsing multiple sclerosis

${ }^{10}$ Interferon- $\beta$

${ }^{11}$ Glatiramer acetate

${ }^{12}$ Alanine

${ }^{13}$ Lysine
}

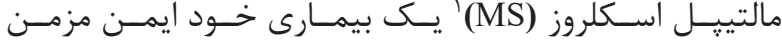

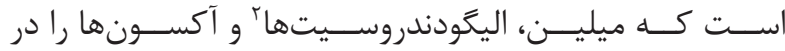

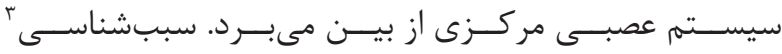

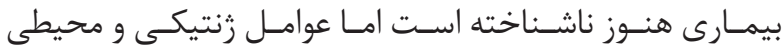

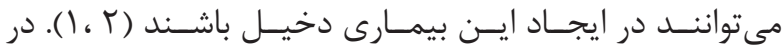

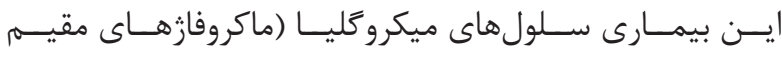

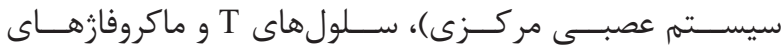

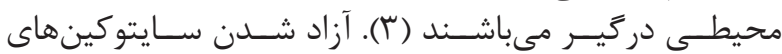

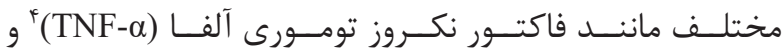

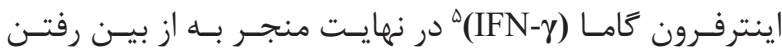

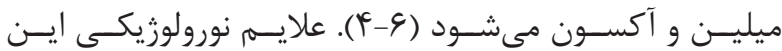

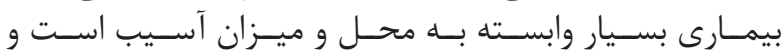

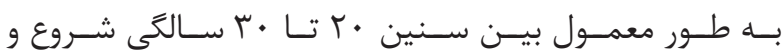

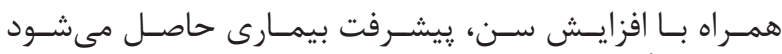

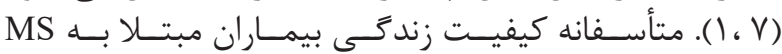

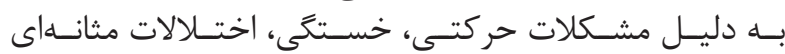

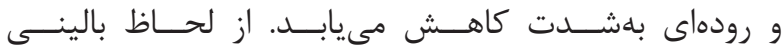

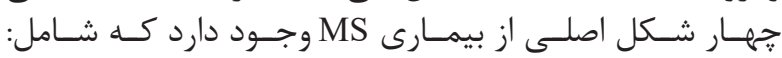

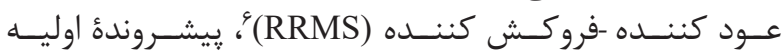

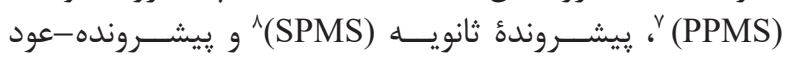

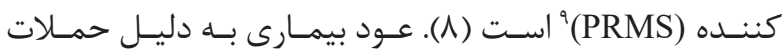

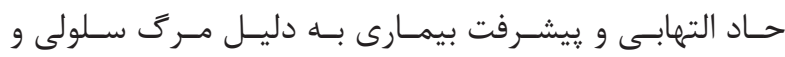

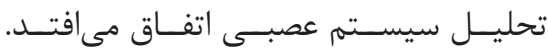

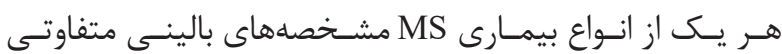

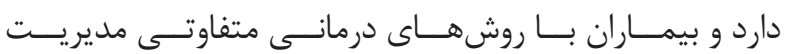

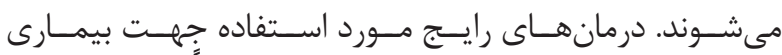

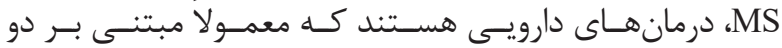

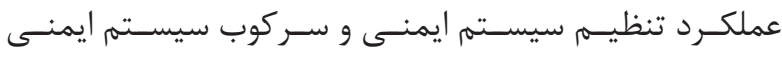

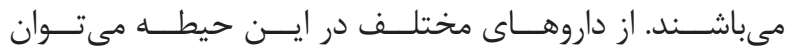

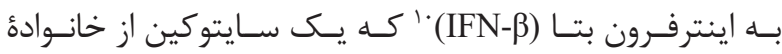

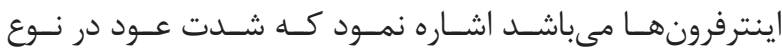

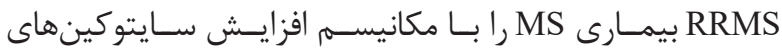

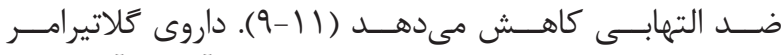

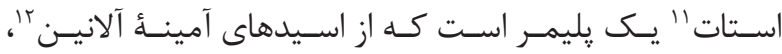

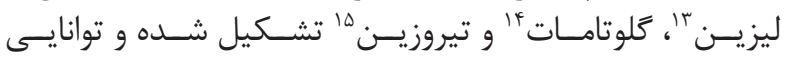

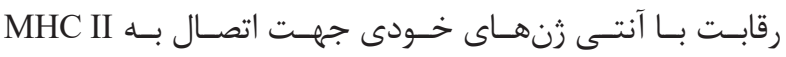

\footnotetext{
${ }^{14}$ Glutamate

${ }^{15}$ Tyrosine

${ }^{16}$ Major histocompatibility complex class II

${ }^{17}$ Natalizumab

${ }^{18}$ Monoclonal

${ }^{19}$ Integrin antagonists $\alpha 4 \beta$

${ }^{20}$ Vascular adhesion molecule

${ }^{21}$ Blood brain barrier

${ }^{22}$ Fingolimod

${ }^{23}$ Sphongosine-phosphate-1-receptor

${ }^{24}$ Alemtuzumab

${ }^{25}$ Cluster of differentiation 52
} 


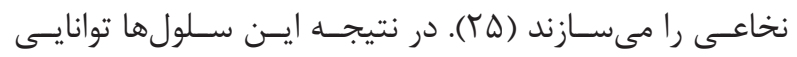

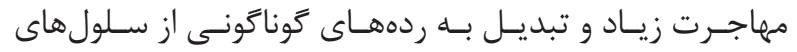

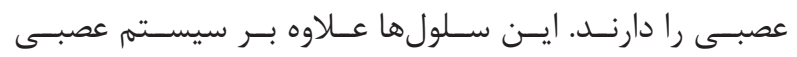

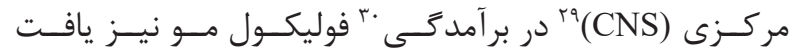

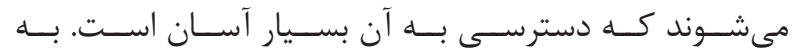

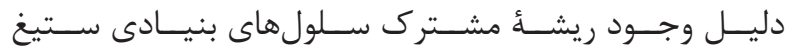

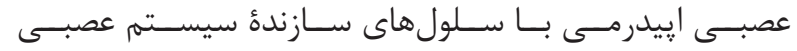

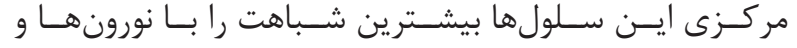

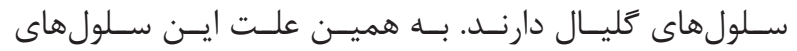

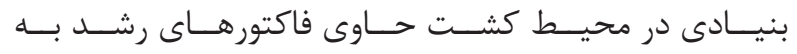

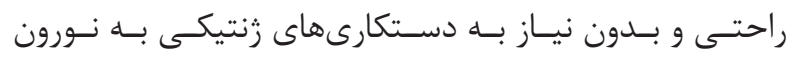

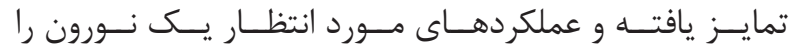

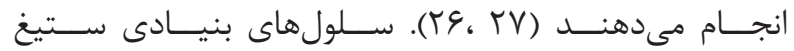

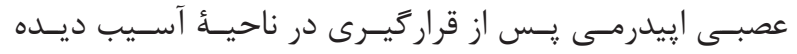

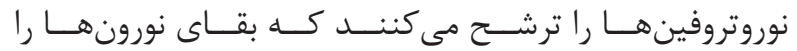

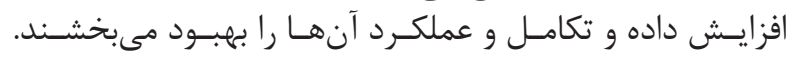

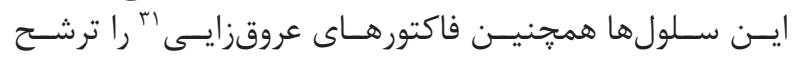

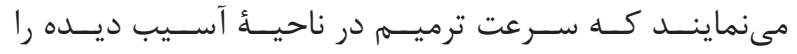

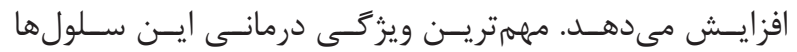

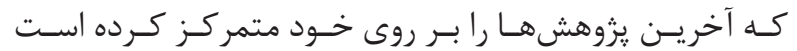

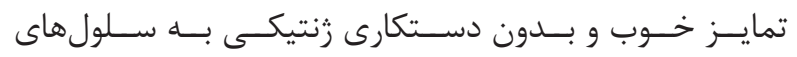

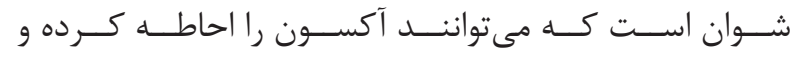

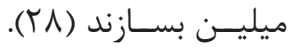

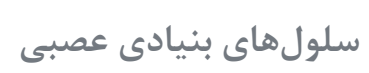

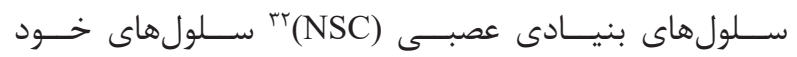

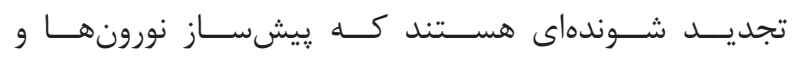

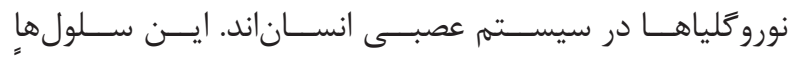

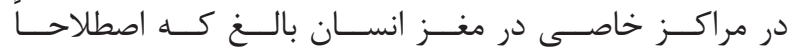

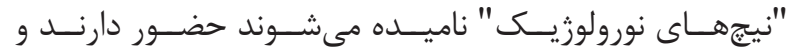

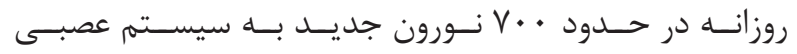

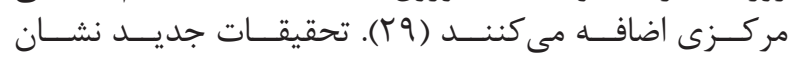

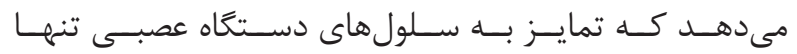

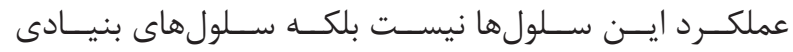

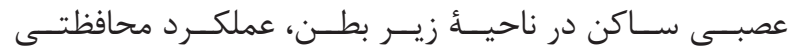

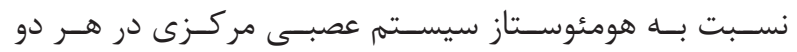

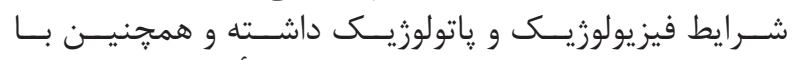

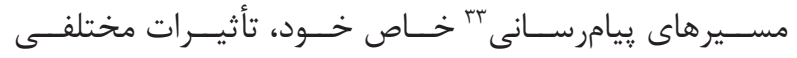

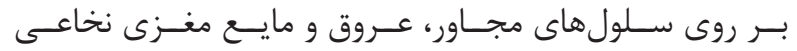

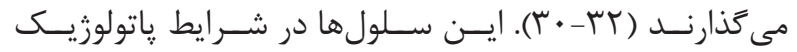

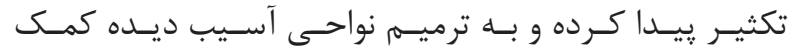

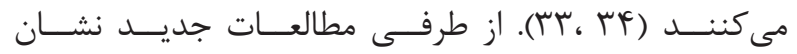

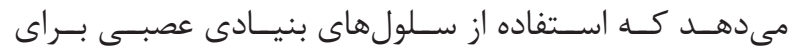

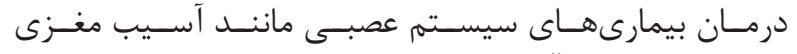

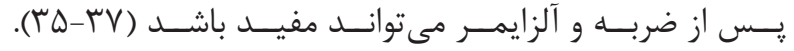

${ }^{26}$ Epidermal neural crest stem cell

${ }^{27}$ The transformation of the neural plate into the neural tube

${ }^{28}$ Neural fold

${ }^{29}$ Central nervous system

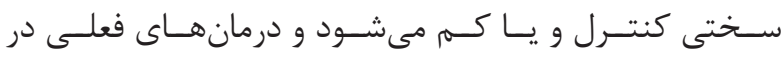

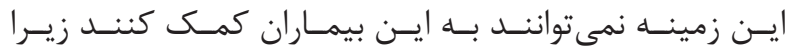

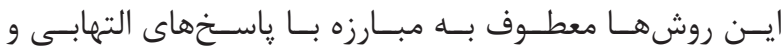

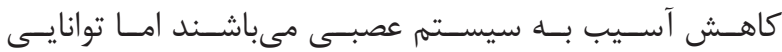

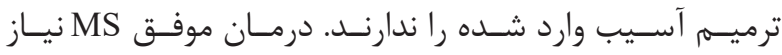

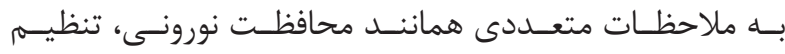

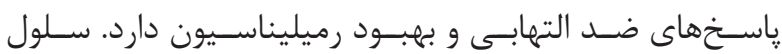

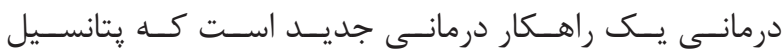

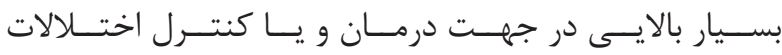

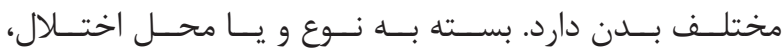

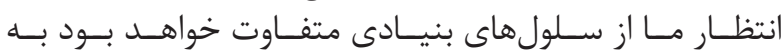

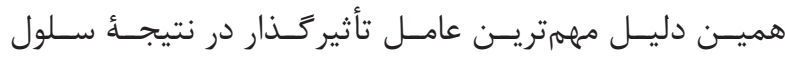

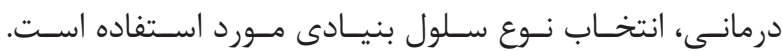

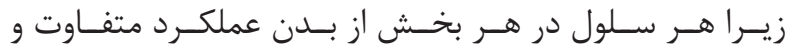

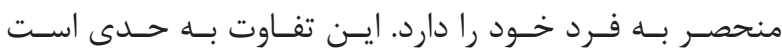

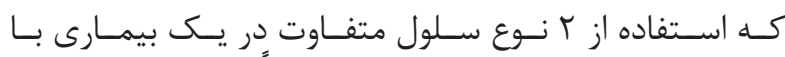

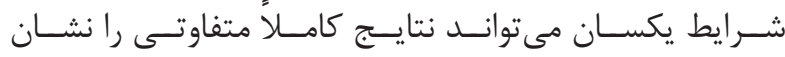

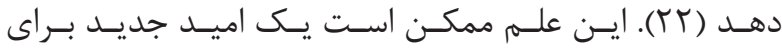

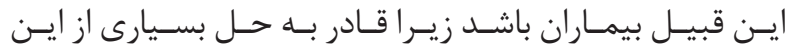

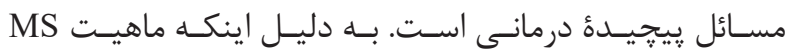

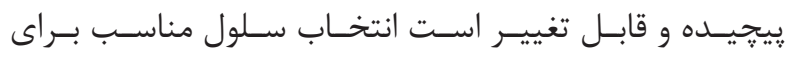

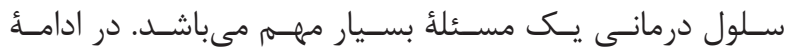

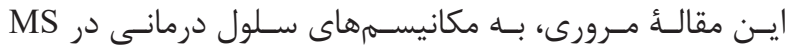

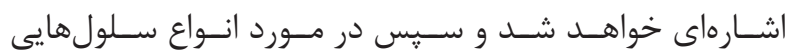

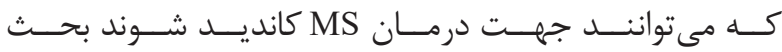

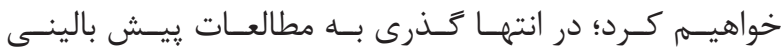

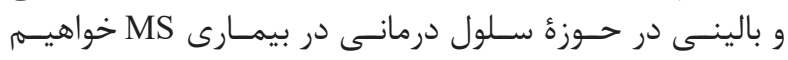
داشت و بالينت

انواع سلولهاى بنيادى در درمان MS

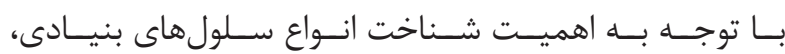

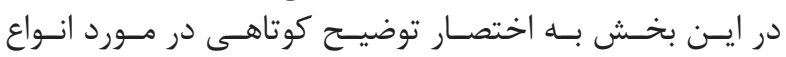

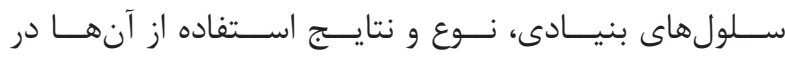

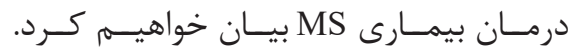
سلول هاى بنيادى ستيغ عصبى إيبدر مى بيدى

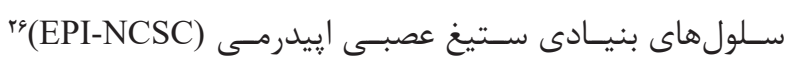

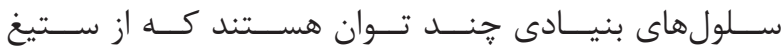

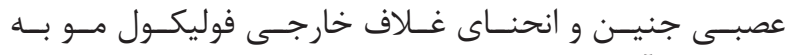

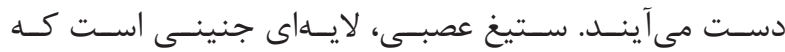

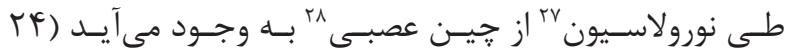

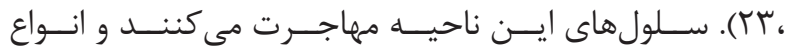

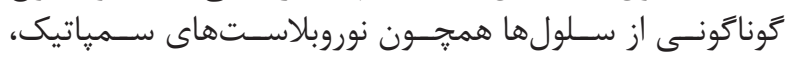

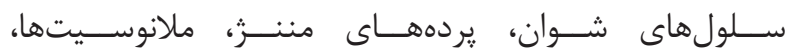

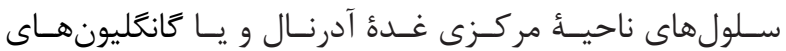

\footnotetext{
${ }^{30}$ Bulge

${ }^{31}$ Angiogenetic factors

${ }^{32}$ Neural stem cells

${ }^{33}$ Signaling
} 


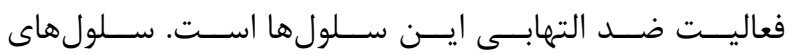

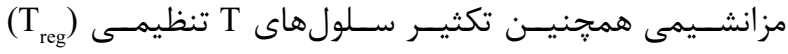

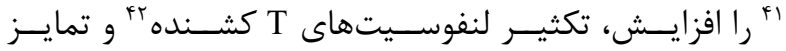

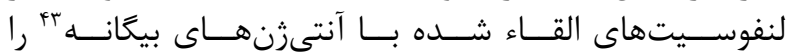

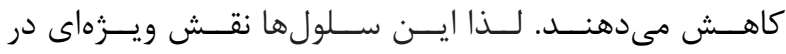

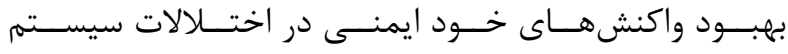

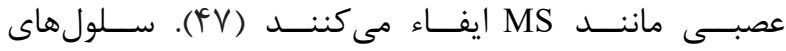

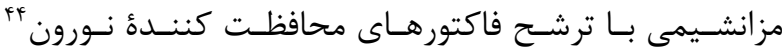

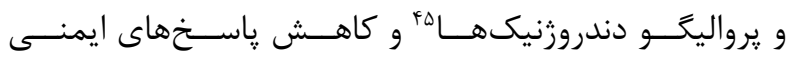

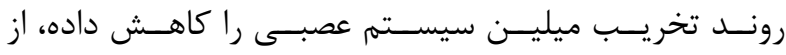

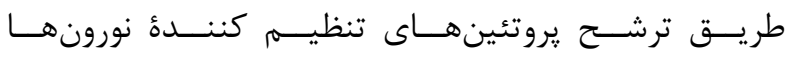

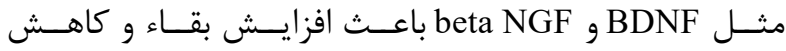

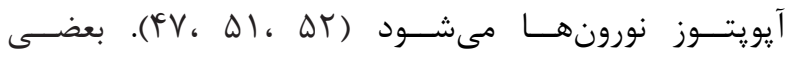

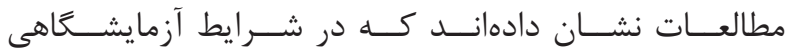

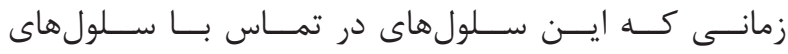

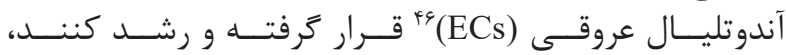

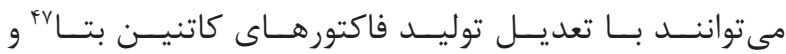

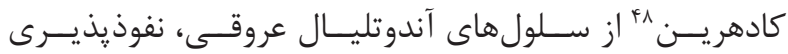

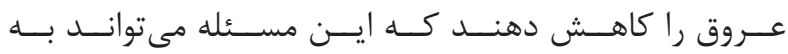

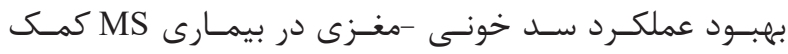

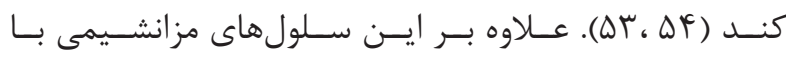

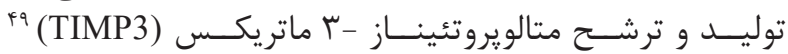

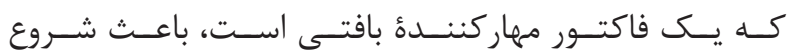

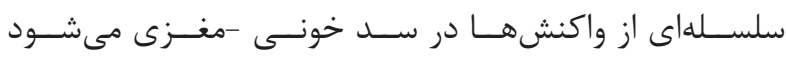

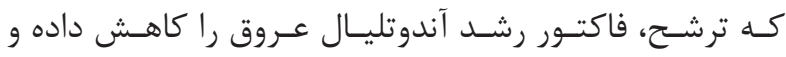

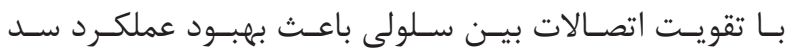

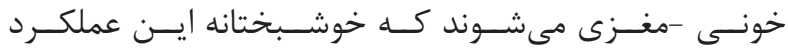

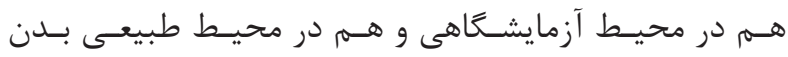

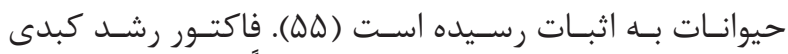

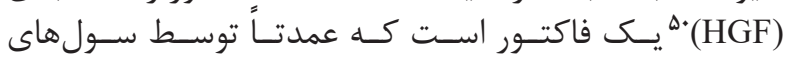

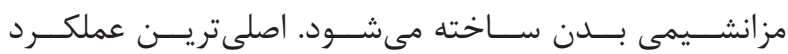

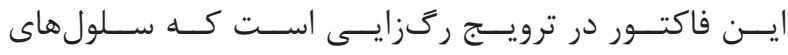

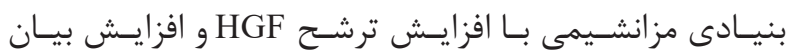

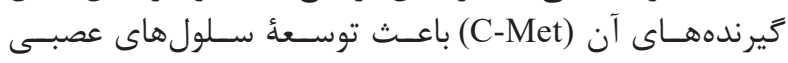

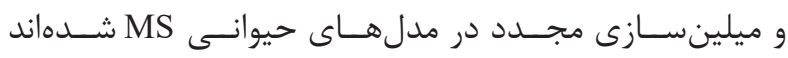

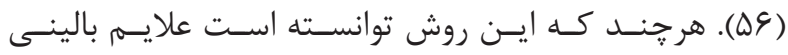

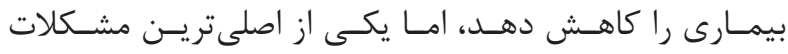

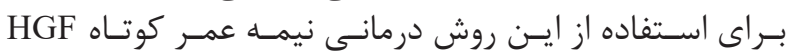

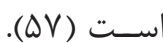

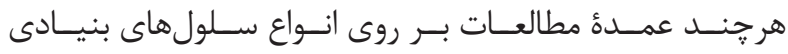

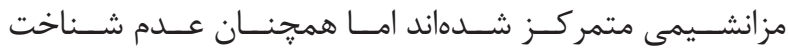

${ }^{34}$ Mesenchymal stem cells

${ }^{35} \mathrm{Graft}$ versus host disease

${ }^{36}$ Immunosuppressive

${ }^{37}$ Fibroblast growth factor

${ }^{38}$ Brain derived growth factor

${ }^{39}$ Antigen presenting cell

${ }^{40}$ Interleukin 4

${ }^{41} \mathrm{~T}$ regulatory cells

${ }^{42}$ cytotoxic T lymphocyte

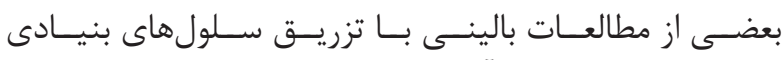

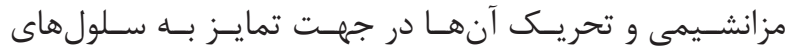

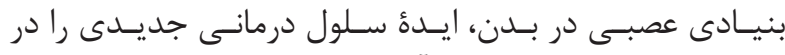

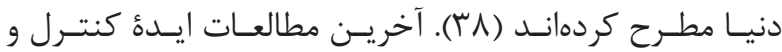

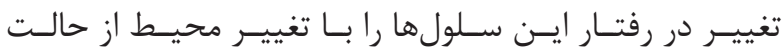

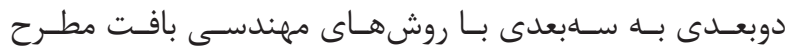

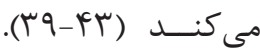

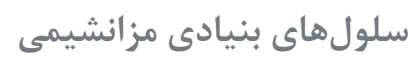

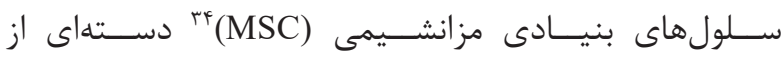

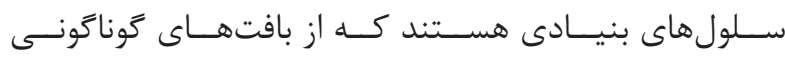

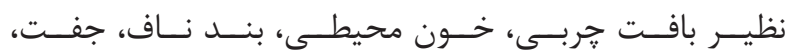

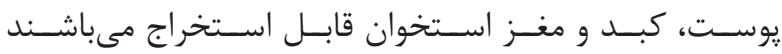

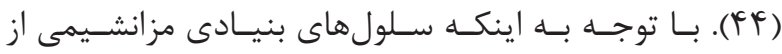

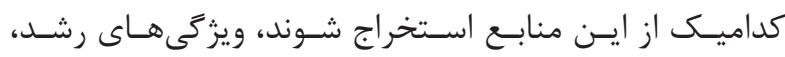

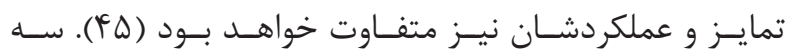

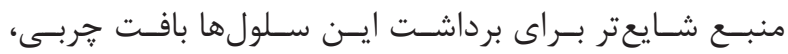

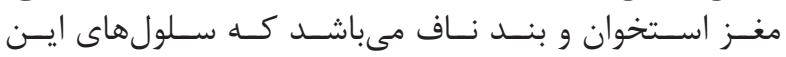

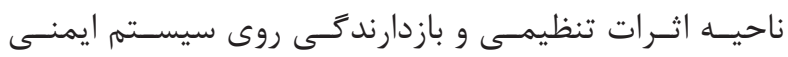

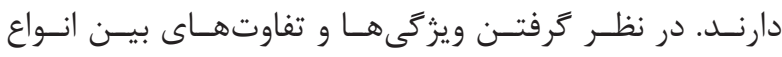

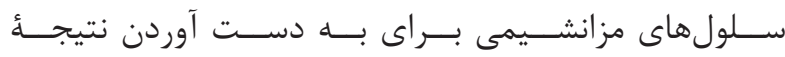

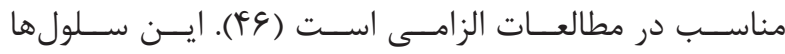

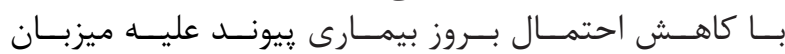

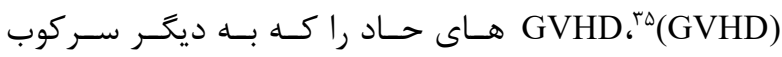

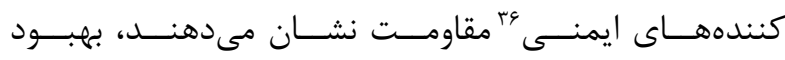

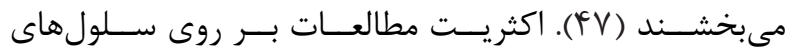

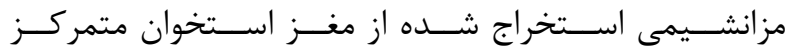

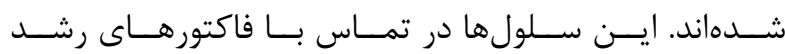

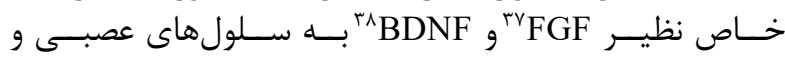

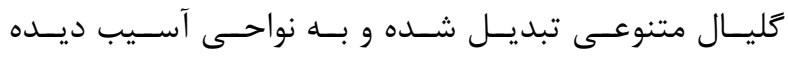

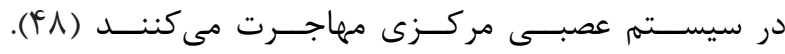

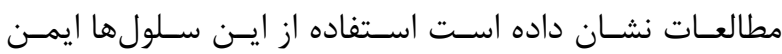

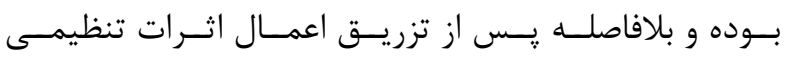

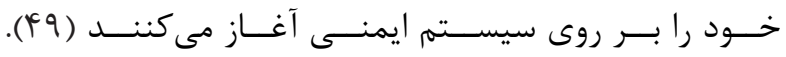

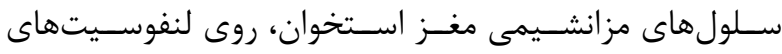

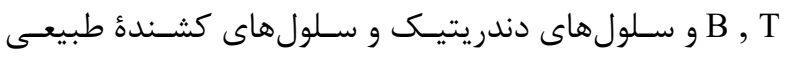

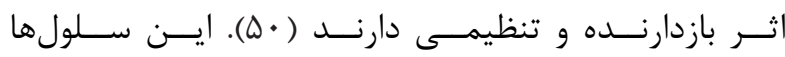

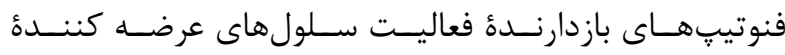

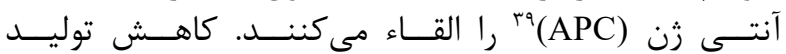

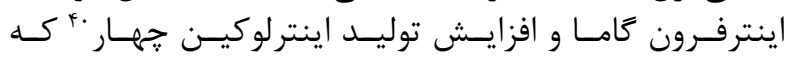

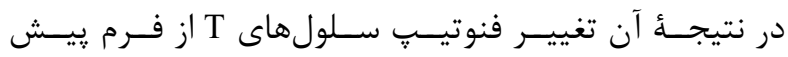

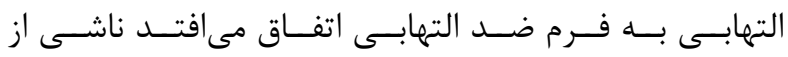

\footnotetext{
${ }^{43}$ Alloantigen induced lymphocyte

${ }^{44}$ Neuroprotective

${ }^{45}$ Pro-oligodendrogenetic

${ }^{46}$ Endothelial stem cell

${ }^{47} \beta$-catenin

${ }^{48}$ Cadherin

${ }^{49}$ Metalloproteinase inhibitor 3

${ }^{50}$ Hepatocyte growth factor
} 


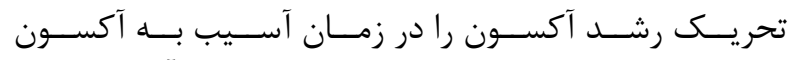

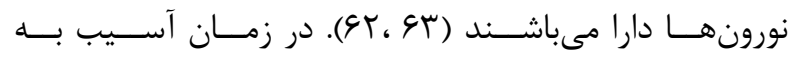

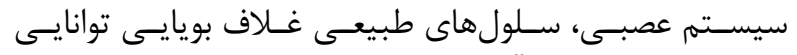

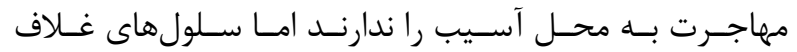

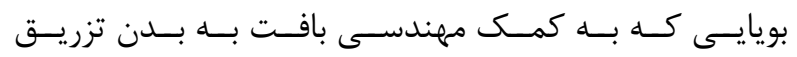

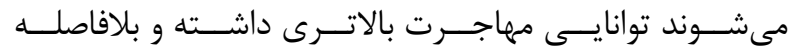

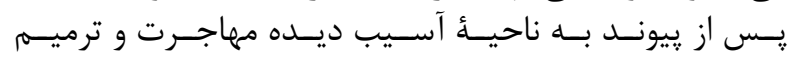

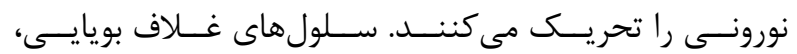

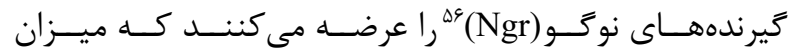

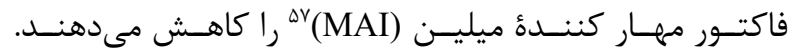

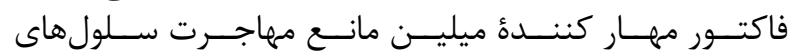

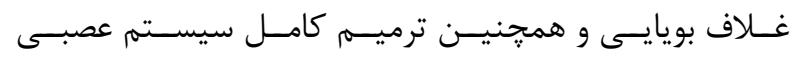

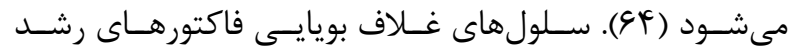

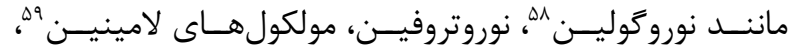

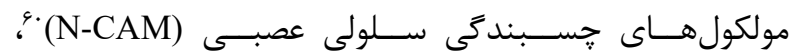

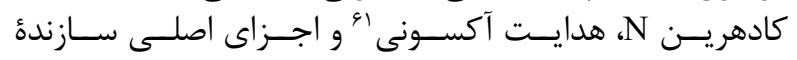

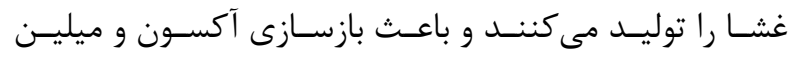

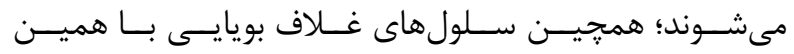

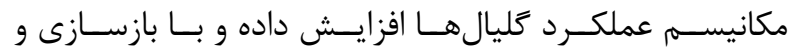

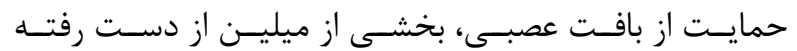

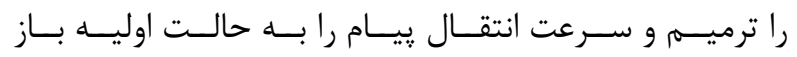

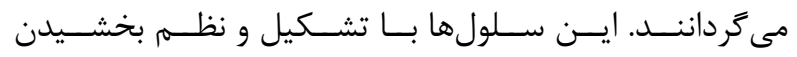

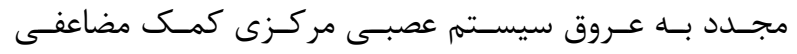

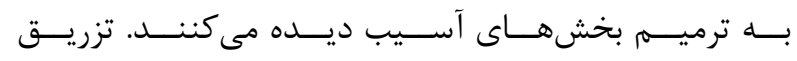

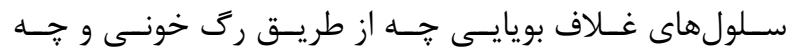

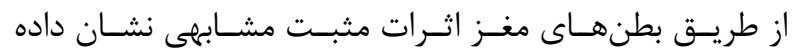

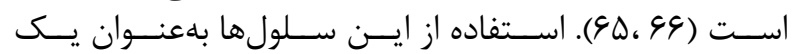

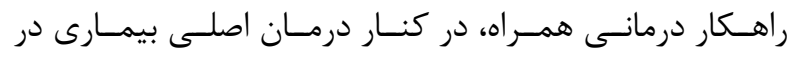

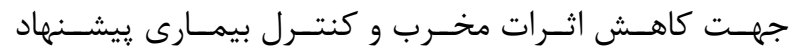
مى شـــود.

\section{سلولهاى بنيادى خونساز}

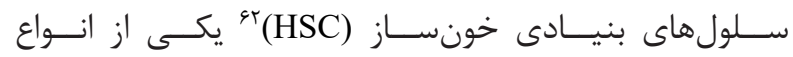

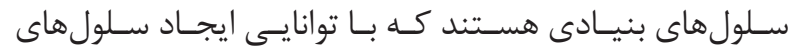

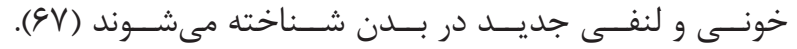

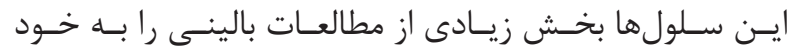

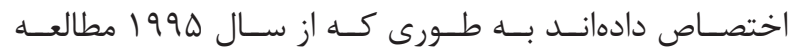

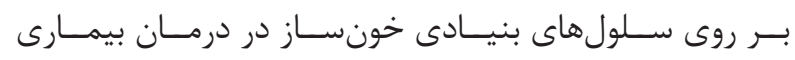

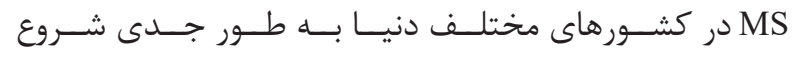

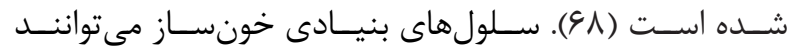

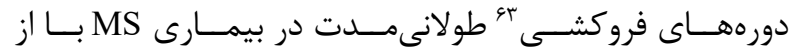

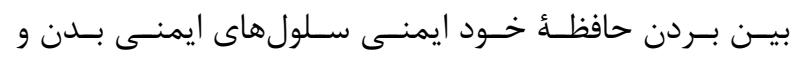

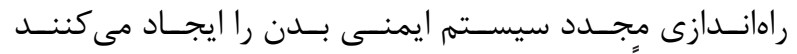

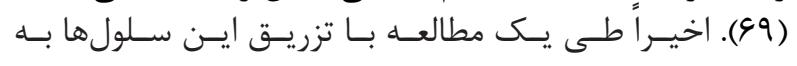

${ }^{51}$ Multipotent adult progenitor cells

${ }^{52}$ Olfactory ensheathing cell

${ }^{53}$ Lamina propria mucosae

${ }^{54}$ Fascicle

${ }^{55}$ Olfactory bulb cells

${ }^{56}$ Nogo receptor

${ }^{57}$ Myelin associated inhibitors
تمـام مكانيسـمها و عملكردهــاى ايـن سـلولها يـس از تزريـق

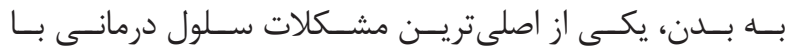

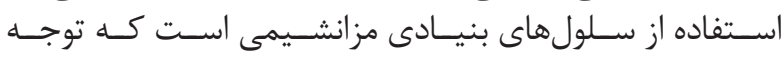

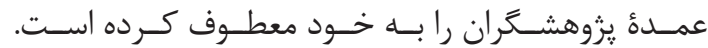
سلول هاى پند توان يِيش ساز بزرَسالان

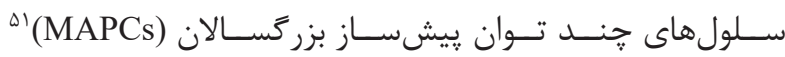

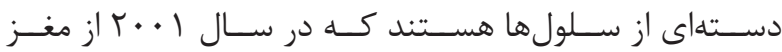

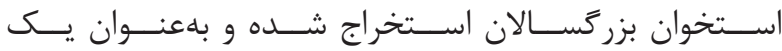

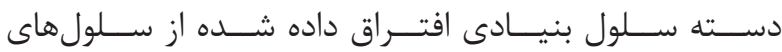

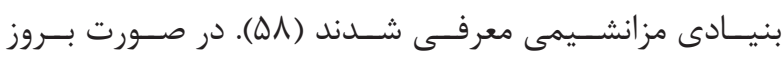

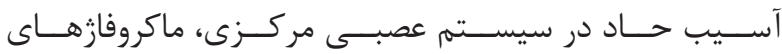

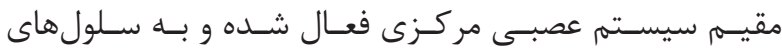

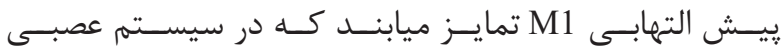

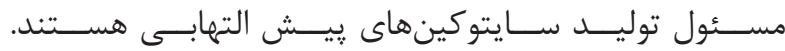

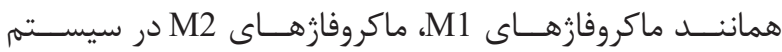

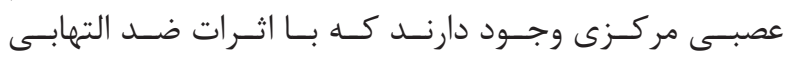

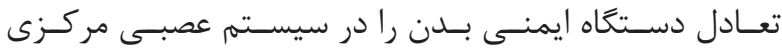

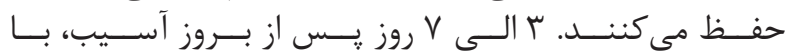

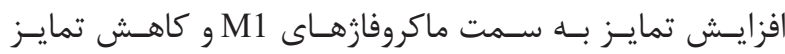

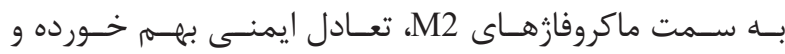

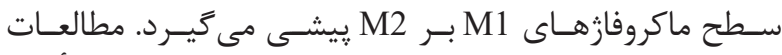

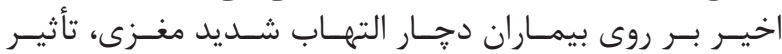

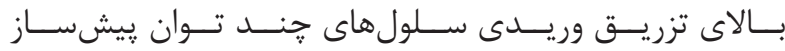

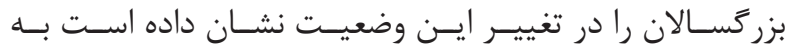

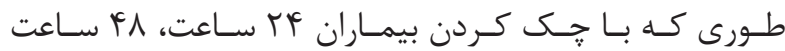

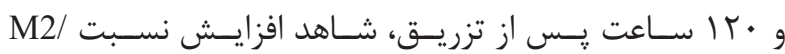

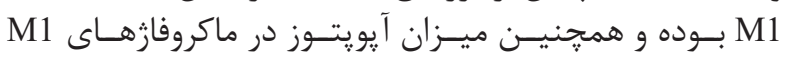

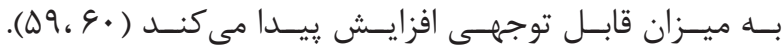

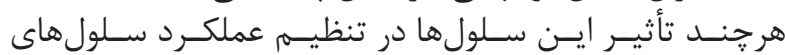

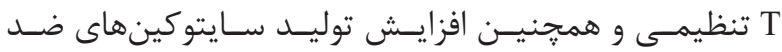

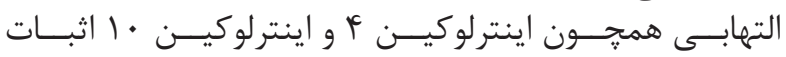

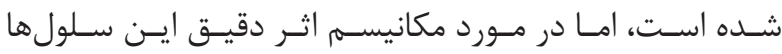

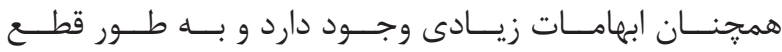

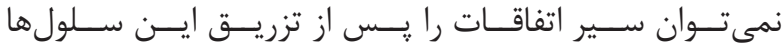

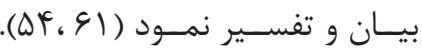

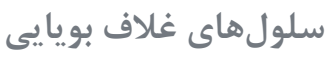

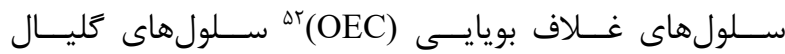

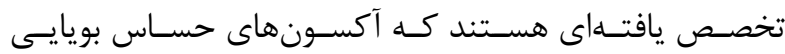

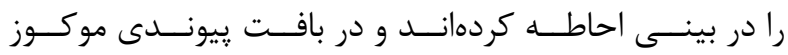

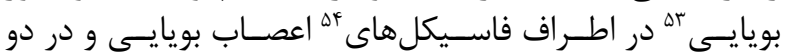

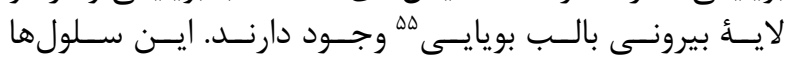

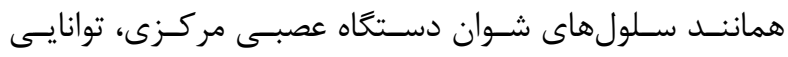

${ }^{58}$ Neurogulins

${ }^{59}$ Laminin

${ }^{60}$ Neural cell adhesion molecules

${ }^{61}$ Axon guidance

${ }^{62}$ Hematopoietic stem cell

${ }^{63}$ Remission 


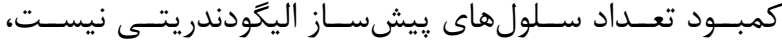

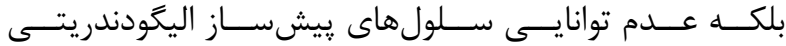

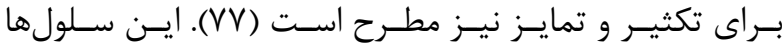

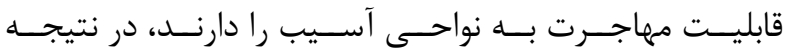

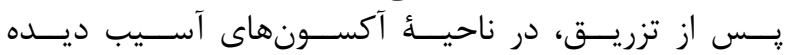

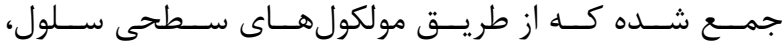

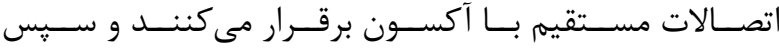

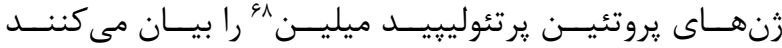
رئ (VA)

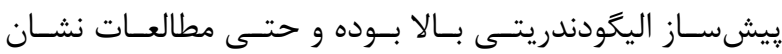

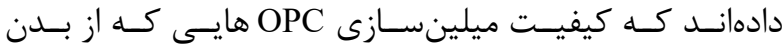

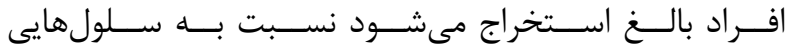

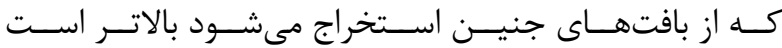

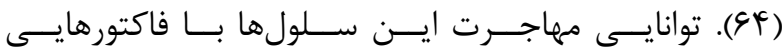

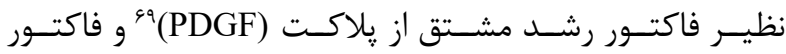

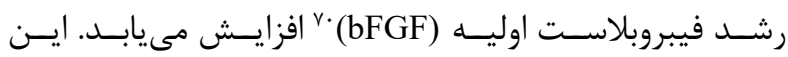

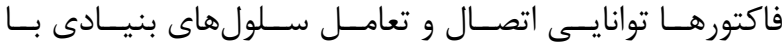

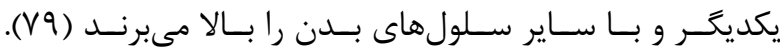

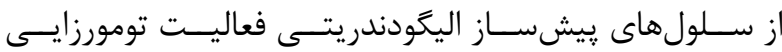

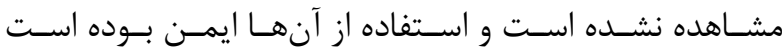

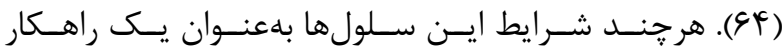

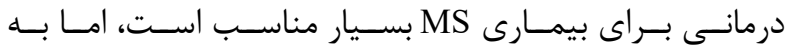

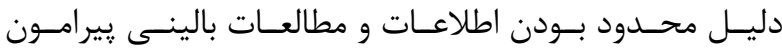

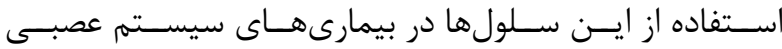

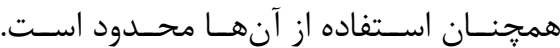

$$
\text { سلول هاى بيش ساز اندو تليال }
$$

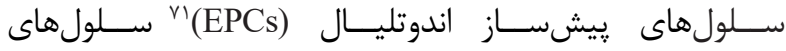

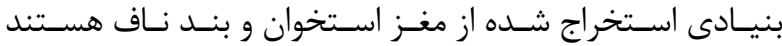

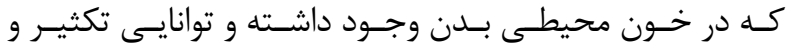

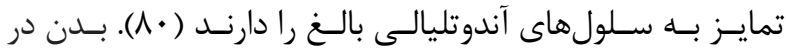

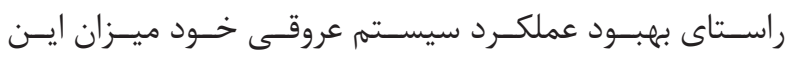

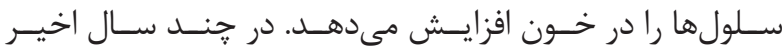

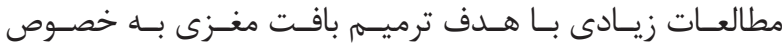

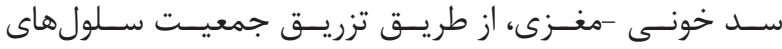

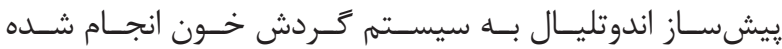

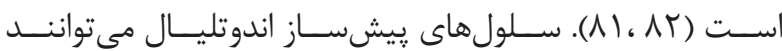

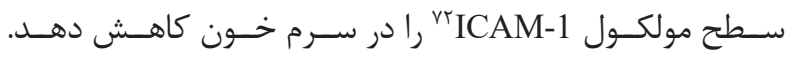

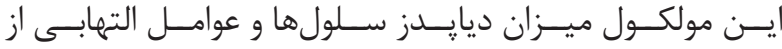

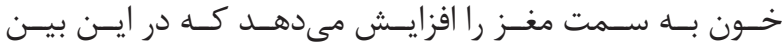

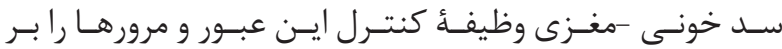

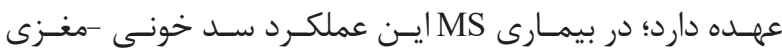

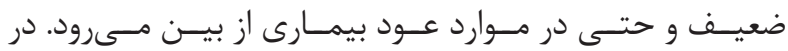

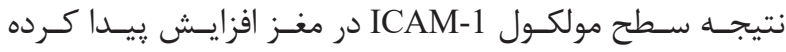

\footnotetext{
${ }^{64}$ Myelin oligodendrocyte glycoproteins

${ }^{65}$ Retrovirus

${ }^{66}$ Experimental autoimmune encephalomyelitis

${ }^{67}$ Oligodendrocyte precursor cells

${ }^{68}$ Myelin proteolipid protein
}

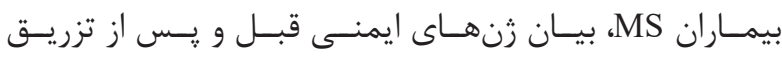

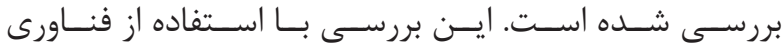

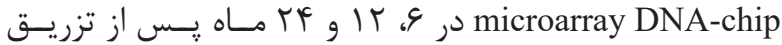

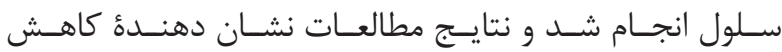

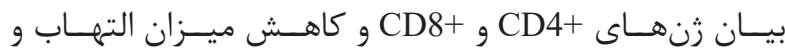

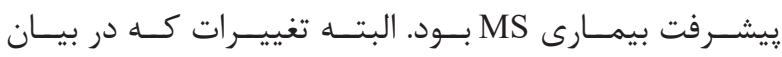

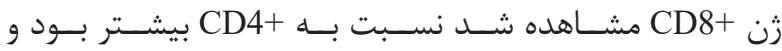

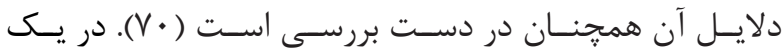

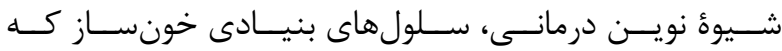

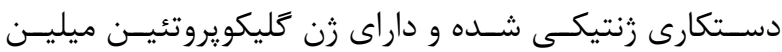

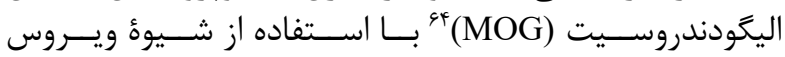

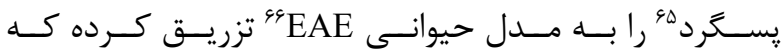

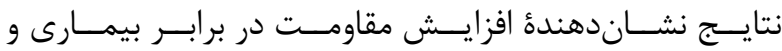

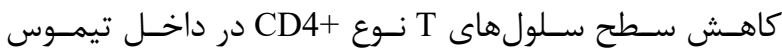

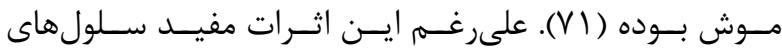

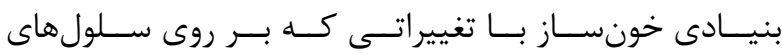

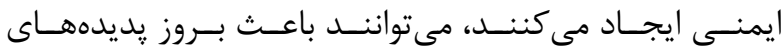

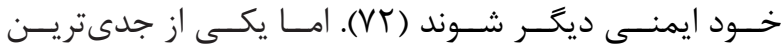

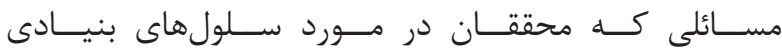

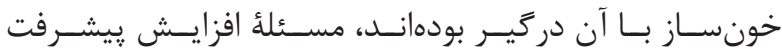

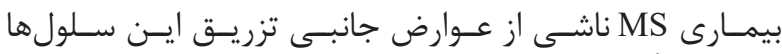

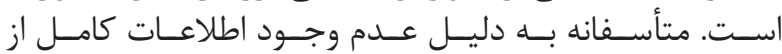

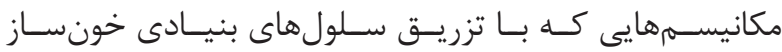

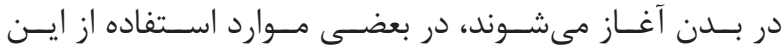

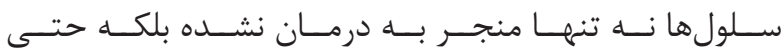

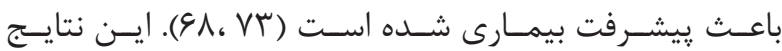

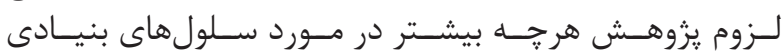

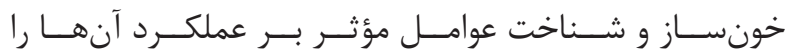

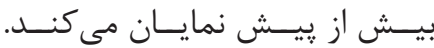

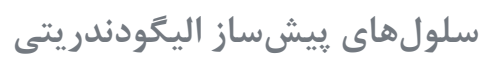

ســلولهاى يِيشســاز الخودندريتـى (OPCs)

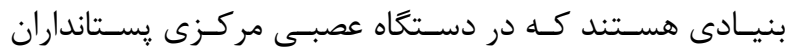

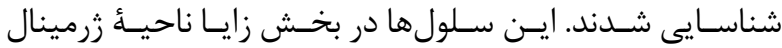

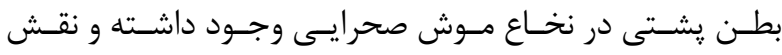

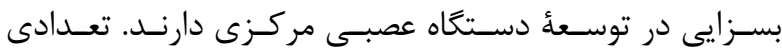

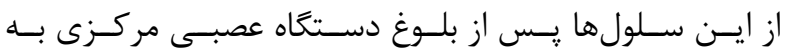

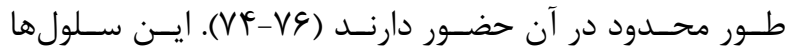

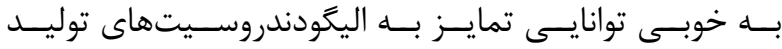

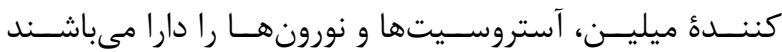

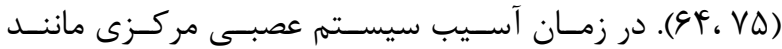

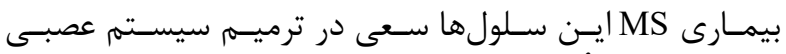

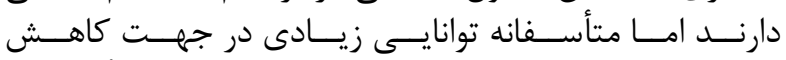

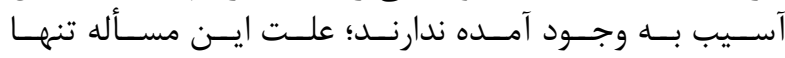

${ }^{69}$ Platelet derived growth factor

${ }^{70}$ Basic fibroblast growth factor

${ }^{71}$ Endothelial progenitor cell

${ }^{72}$ Intercellular adhesion molecule 1 


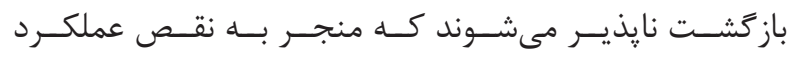

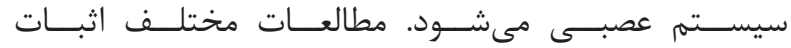

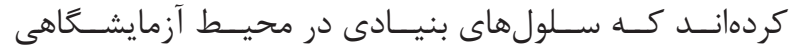

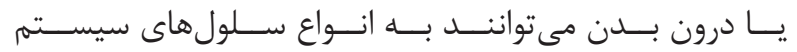

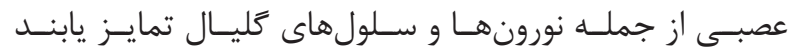

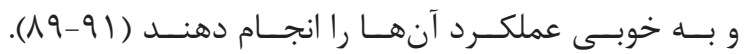

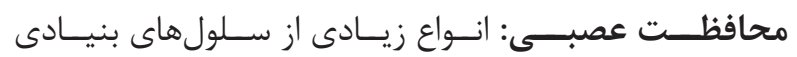

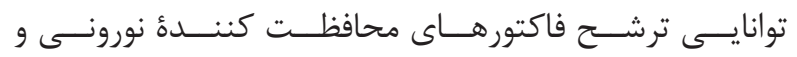

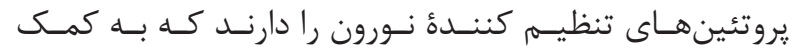

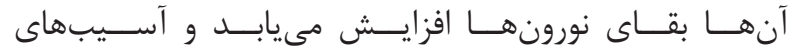

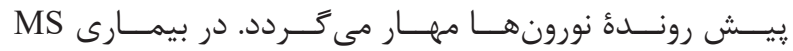

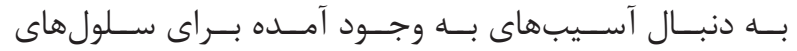

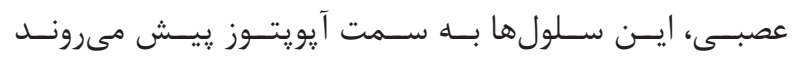

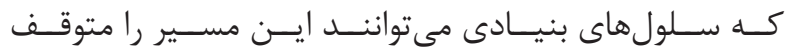

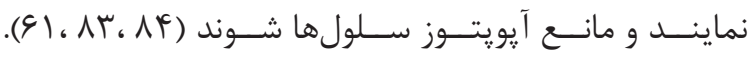

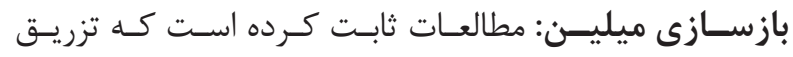

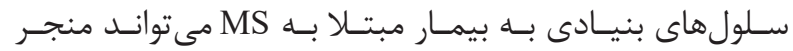

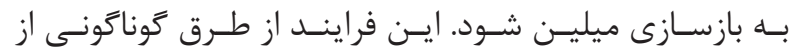

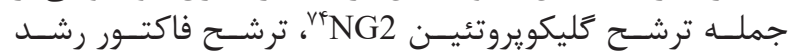

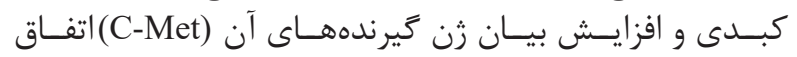

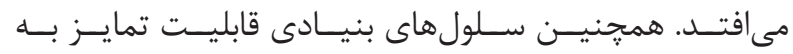

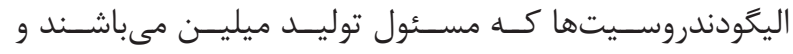

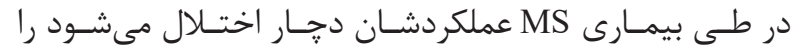

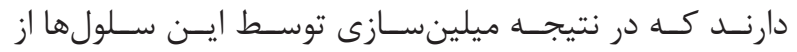

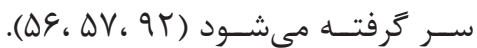

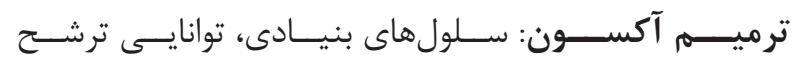

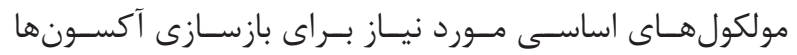

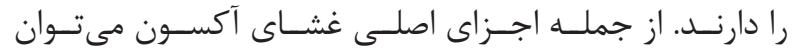

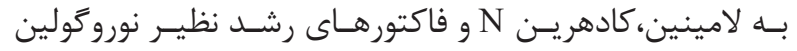

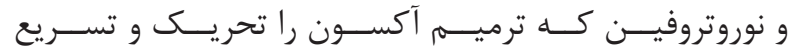

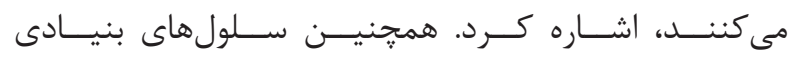

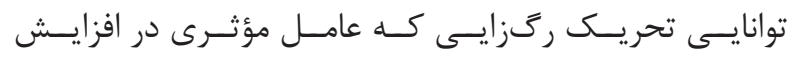

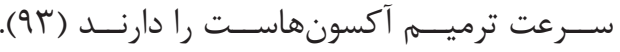

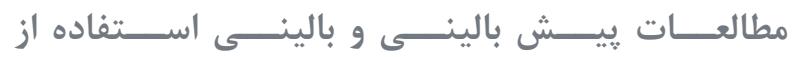

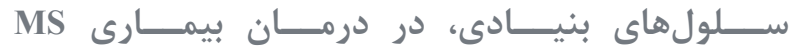
مطالعات بيش بالينى

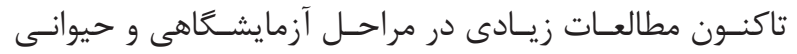

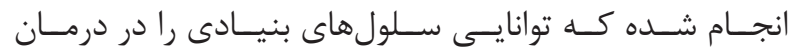

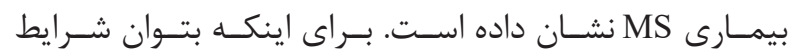

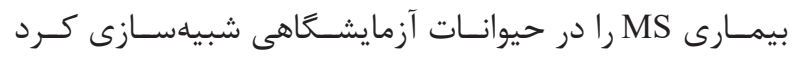

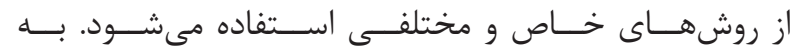

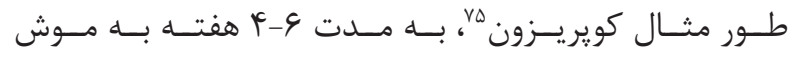

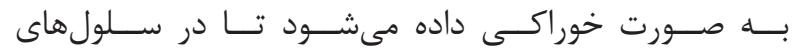

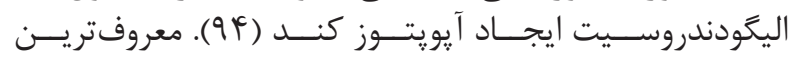

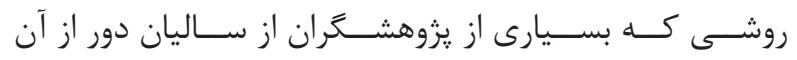

${ }^{73}$ Outgrowth endothelial cells

${ }^{74} \mathrm{Neural} /$ glial antigen 2

${ }^{75}$ Coprizon

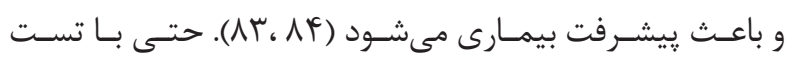

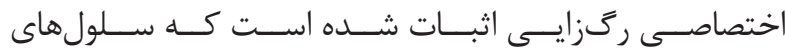

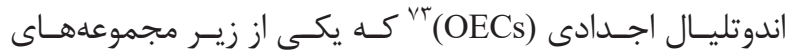

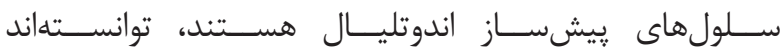

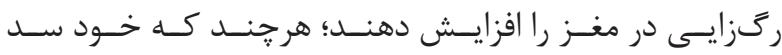

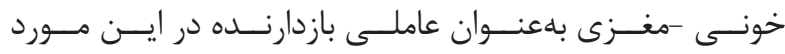

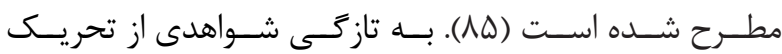

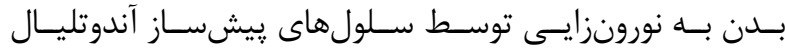

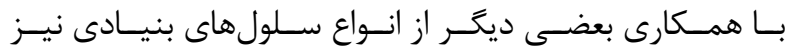

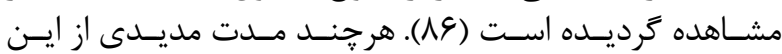

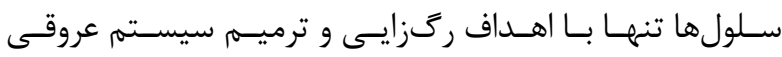

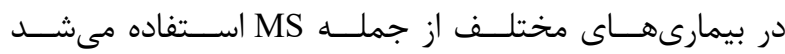

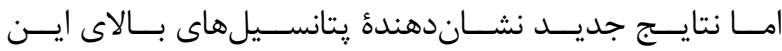

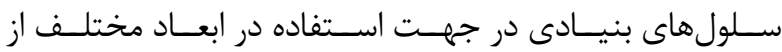

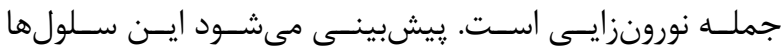

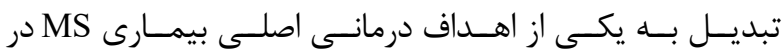

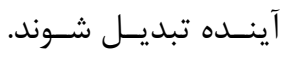
مكانيسمههاى سلول درمانى در

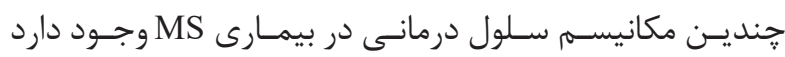

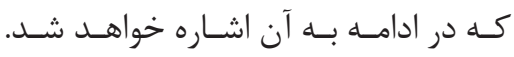

كاهــش التهـهـاب: كـهـ بــه دو صــورت بهبــود عملكـرد ســد

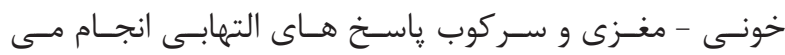
خيـرد.

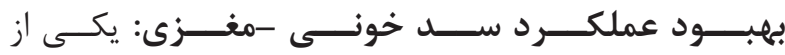

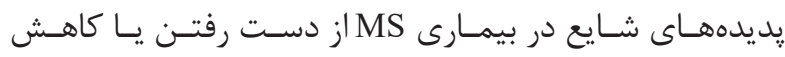

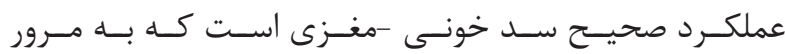

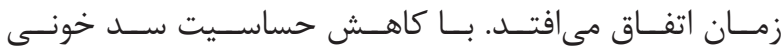

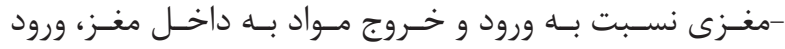

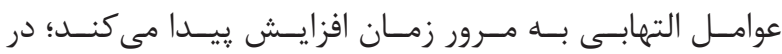

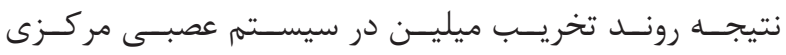

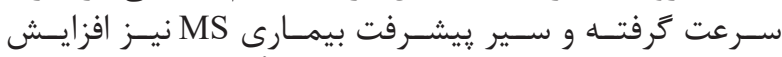

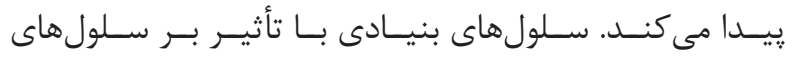

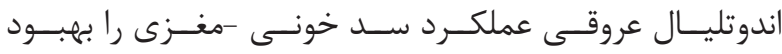

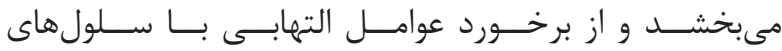
عصبــى مى كاهنـــد (DV، AV).

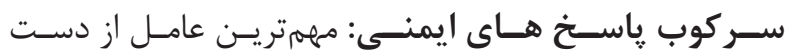

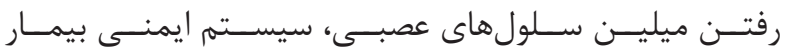

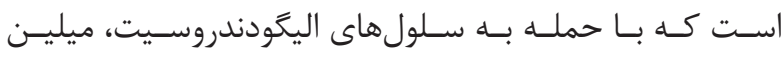

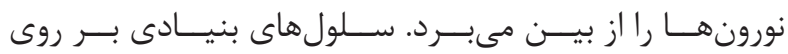

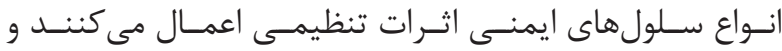

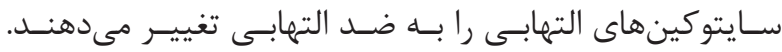

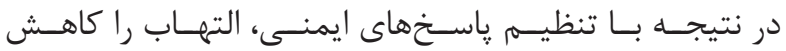

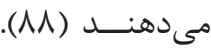

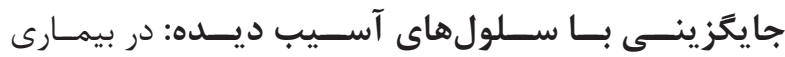

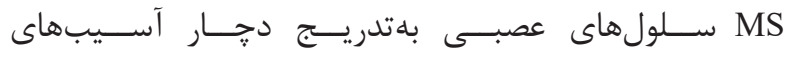




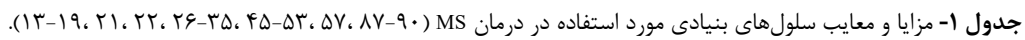

\begin{tabular}{|c|c|c|}
\hline معايب & مزايا & سلول \\
\hline تمايز كمي به نورون & 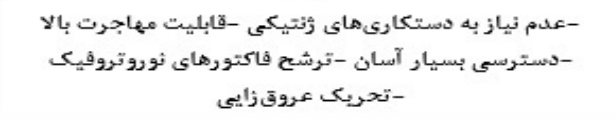 & سلولهاى بنيادى ستيغ ابيدرمى \\
\hline فياز به دستكارى رُنتيكى دارند & 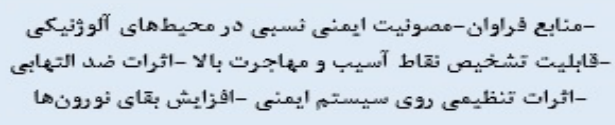 & سلولهاى بنيادى مزاتشيعى \\
\hline طرفيت ترميهم محدلون & 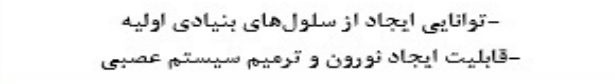 & سلولهاي بنيادى عصبى \\
\hline ايجاد يكى سرى حركات غيرارادى & 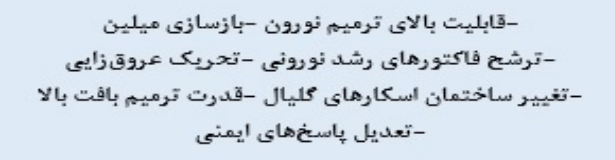 & سلولهاي عَالاق بويايى \\
\hline المكان ايجاد واكنش هاي خودايمنى & 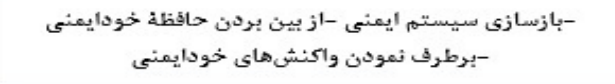 & سلول هاى بنيانى خون ساز \\
\hline 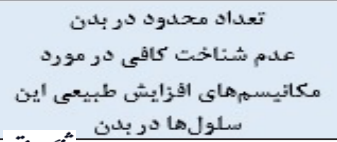 & - قدرت ميلينسازى بسيار بالا - توانايعى ميهاجرت & سلولهاى بيشى ساز \\
\hline
\end{tabular}

\section{كار آزمايى هاى بالينى}

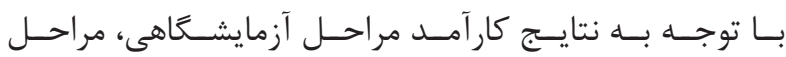

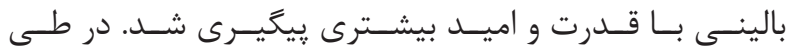

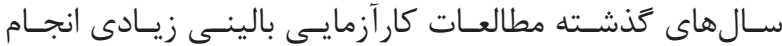

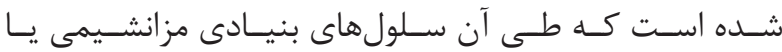

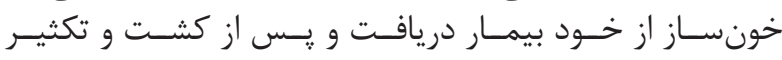

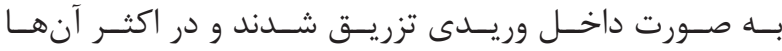

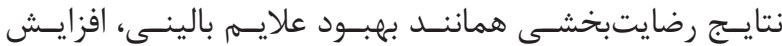

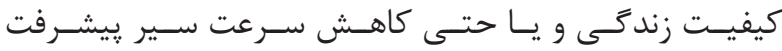

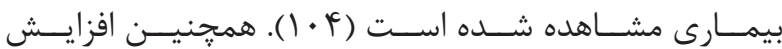

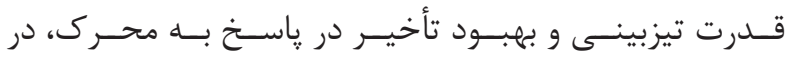

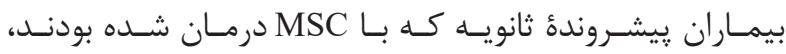

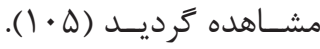

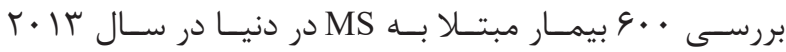

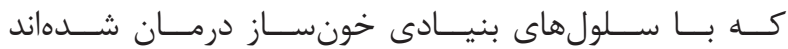

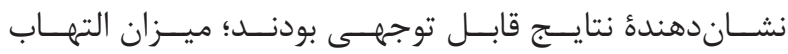

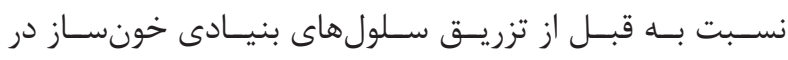

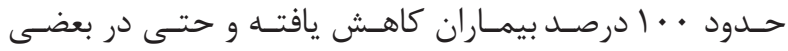

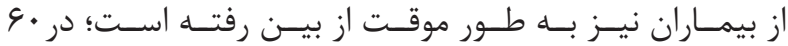

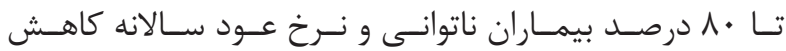

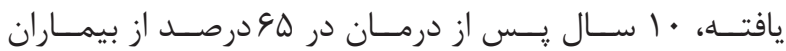

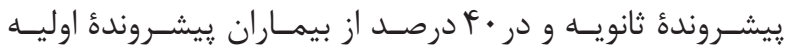

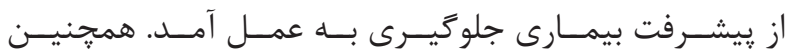

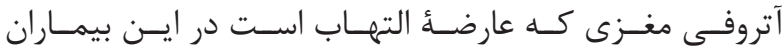
كاهـش يافتــه اسـت (أ •(1).

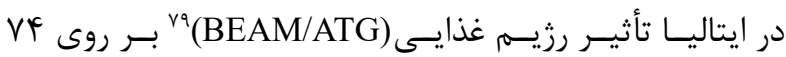

\footnotetext{
${ }^{76}$ Demyelination

${ }^{77}$ Oligodendrocyte progenitor cells
}

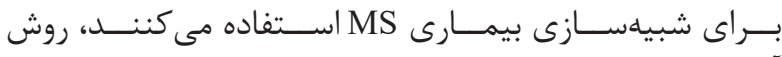

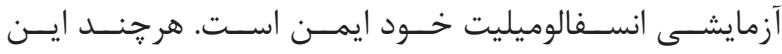

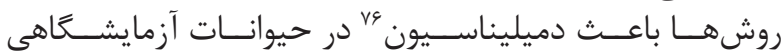

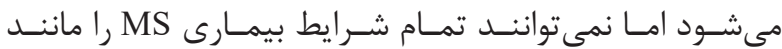

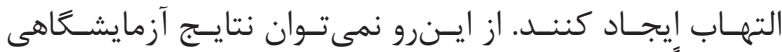

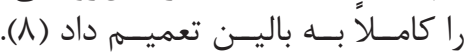

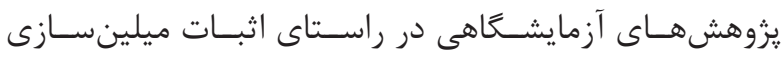

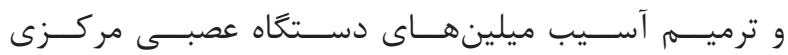

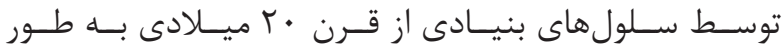

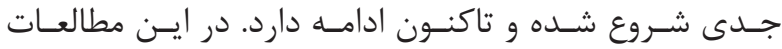

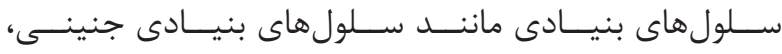

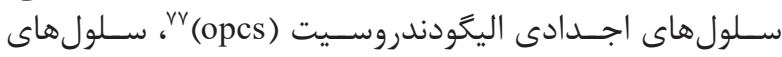

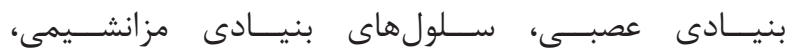

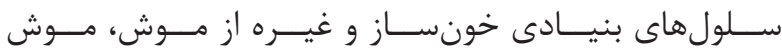

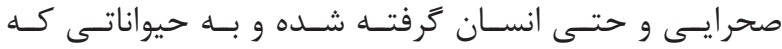

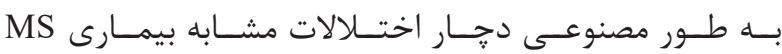

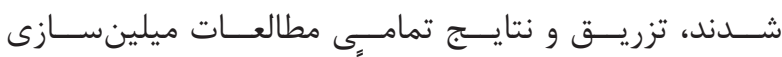

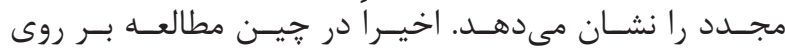

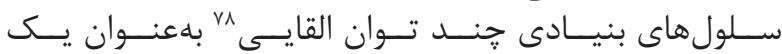

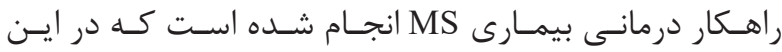

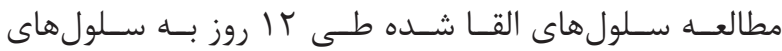

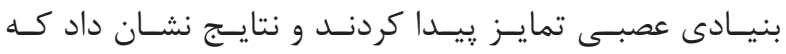

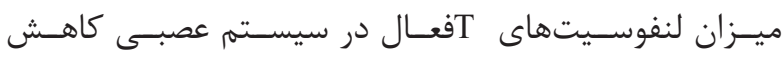

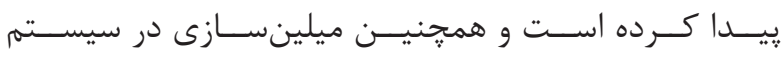

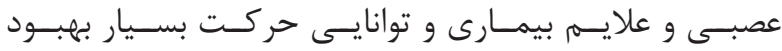

يافتـه اسـت (91) - (91).

\footnotetext{
${ }^{78}$ Induce pluripotent stem cell

${ }^{79} \mathrm{BCNU}$ (carmustine), cytarabine, etoposide, melphalan / antithymocyte globulin
} 
جدول r- استفاده از سلولهاى بنيادى در مطالعات تجربى جهت تأثير بر ميلينسازى.

\begin{tabular}{|c|c|c|c|c|}
\hline مثابع & ثتايج & 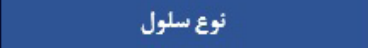 & 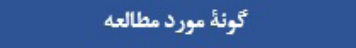 & 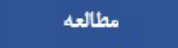 \\
\hline (१४) & بيبود ميلينسازى & سلولهاى اجدادى اليُّودندروسيت موش & $\begin{array}{l}\text { موش صحرايی، داراى نقص ميلينسازى } \\
\text { (Myelin Deficient) }\end{array}$ & اسيينوزا و همكاران \\
\hline (११) & بيبود ميلينسازى & سلولهاى بئيادى عصبيى موش & 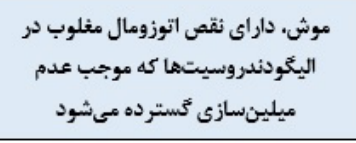 & يائداوا و همكاران \\
\hline$(1 \bullet)$ & بهبود ميلينسازى & سلولهاى بنيادى رويائى موش & موش صحرايى، آسيب نخاع با اتيديوم & ليو و همكاران \\
\hline (१9) & بهبود ميلينسازى & سلولهاى بنيادى مزانشيمال موش & موش صحرايى، آسيب نخاع با اتيديوم & آكياما و همكاران \\
\hline$(1-1)$ & بهبود ميلينسازى & سلولهاى بنيادى رويائى موش & موش صحر ايى، جهش ثقص ميلينسازى & كلسر و همكاران \\
\hline$(1+r)$ & بيبود ميلينسازى & سلولهاى اجدادى اليكودندروسيت انسان & 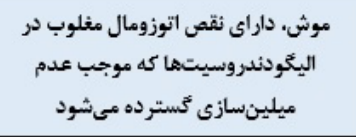 & ويندرم و همكاران \\
\hline$(1+r)$ & بيبود ميلينسازى & سلولهاى بنيادى رويائى اثسائى & موش صحرايى، آسيب نخاع با اتيديوم & كمكاران \\
\hline (१४) & بيبود ميلينسازى & سلولهاى اجدادى عصبى موش & موش، آسيب جسهم يِينهاى باكويريزون & كويرى و همكاران \\
\hline
\end{tabular}

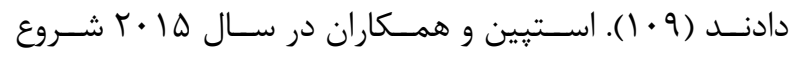

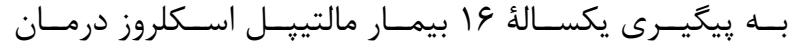

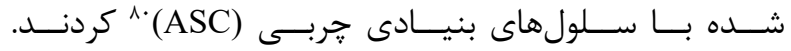

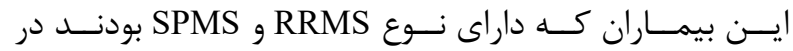

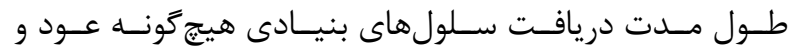

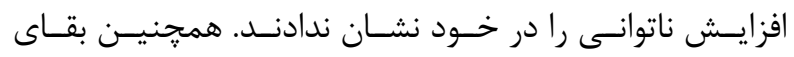

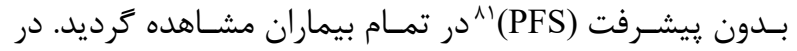

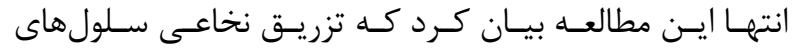

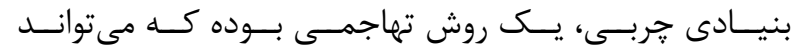

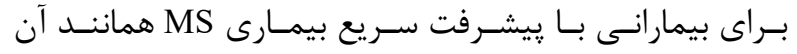

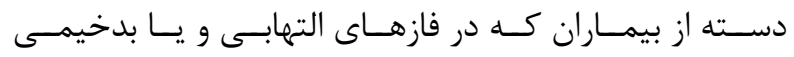

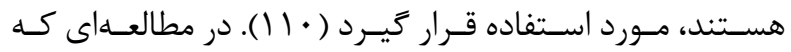

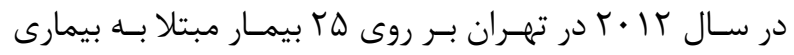

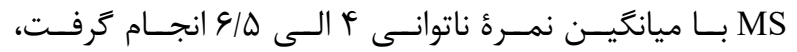

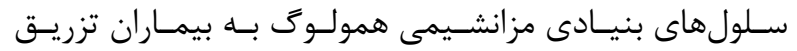

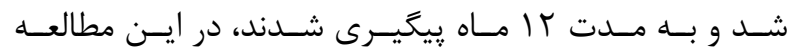

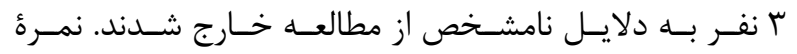

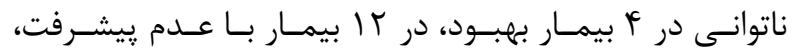

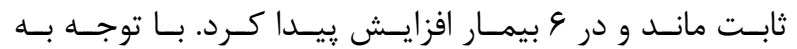

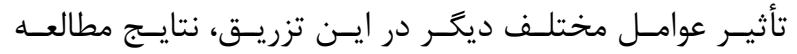

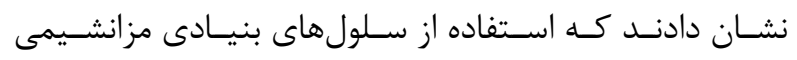

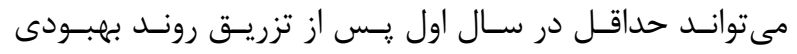

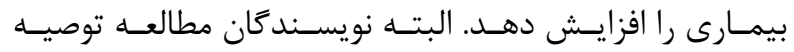

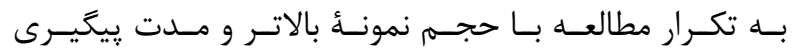

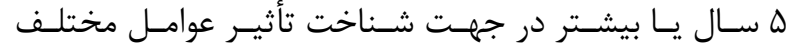

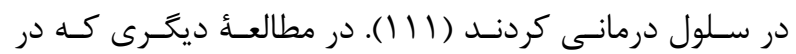

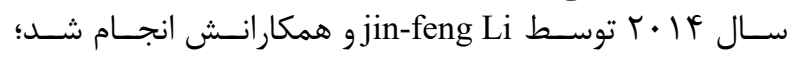

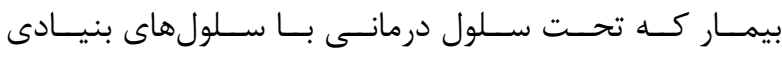

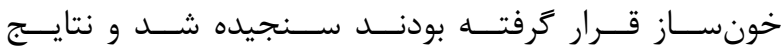

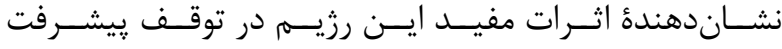

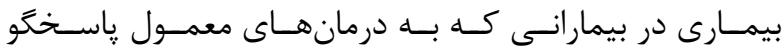

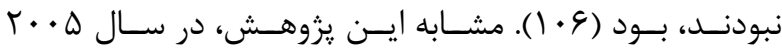

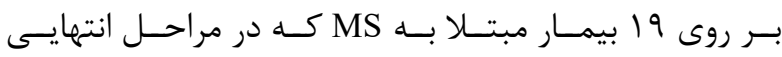

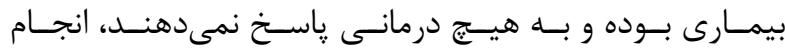

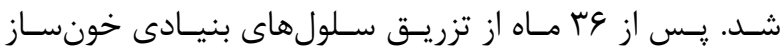

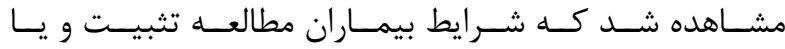

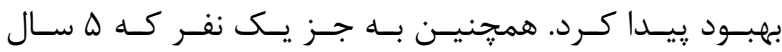

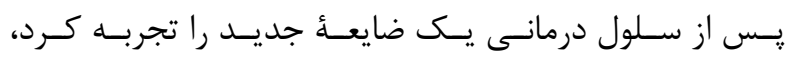

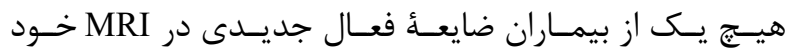

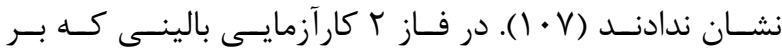

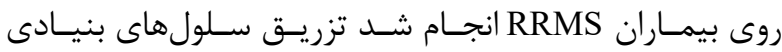

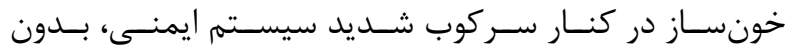

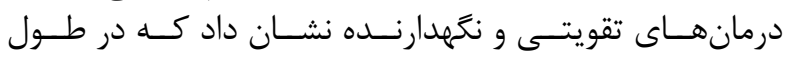

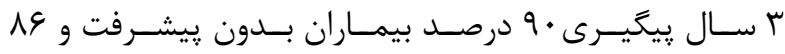

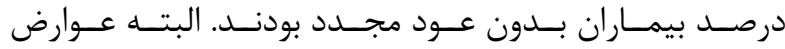

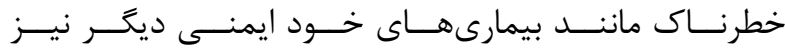

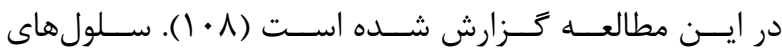

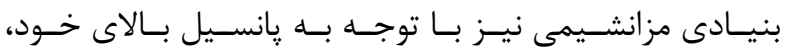

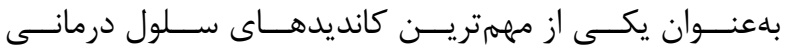

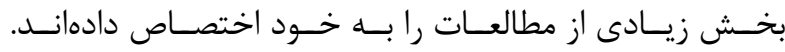

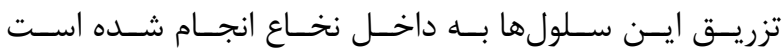

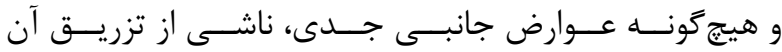

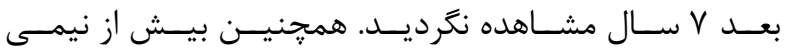

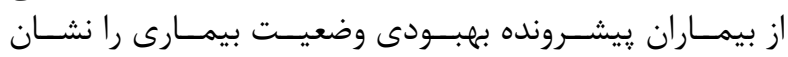




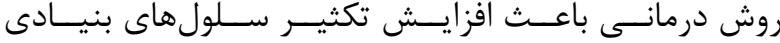

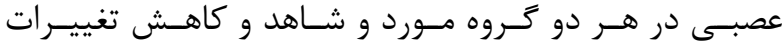

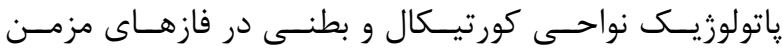

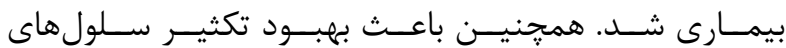

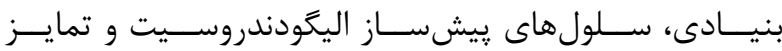

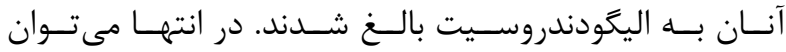

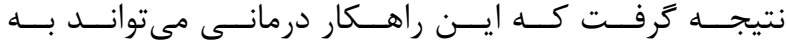

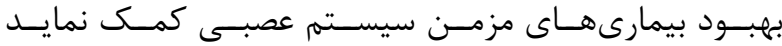

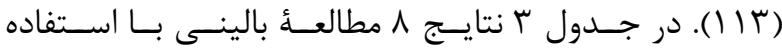

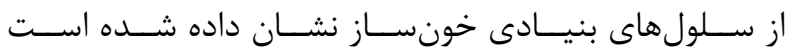

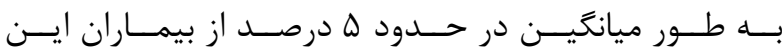

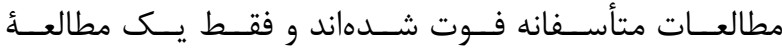

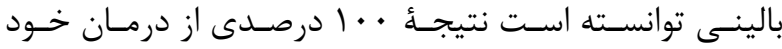

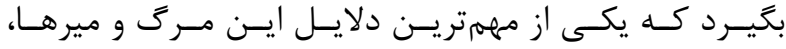

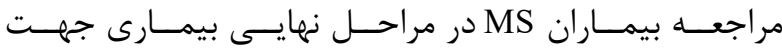

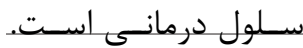

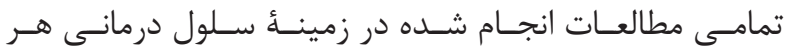

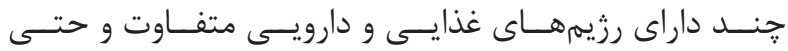

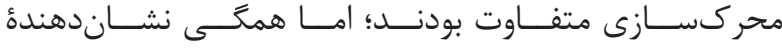

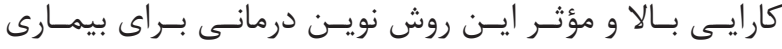

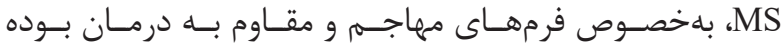

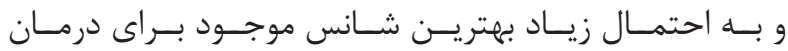

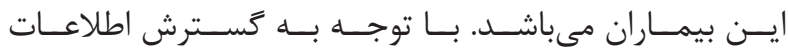

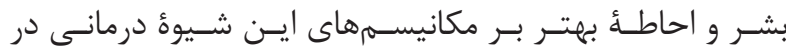

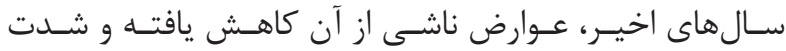

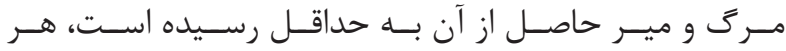

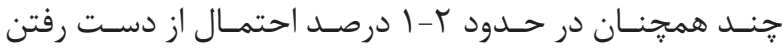

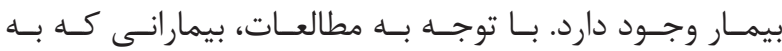

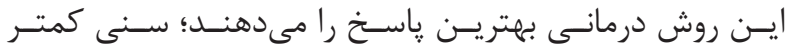

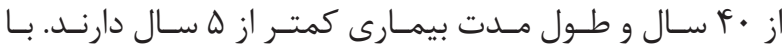

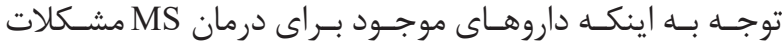

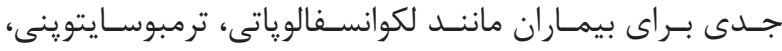

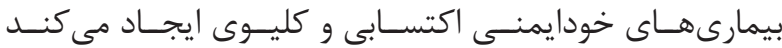

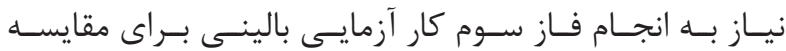

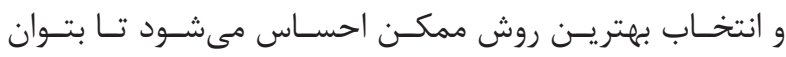

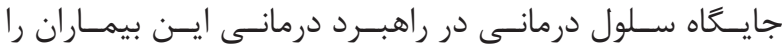
مشـخص كـرد.

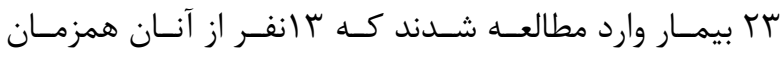

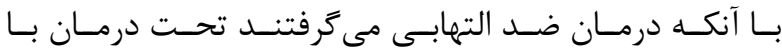

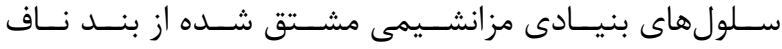

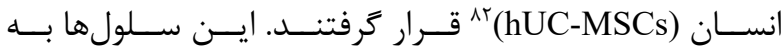

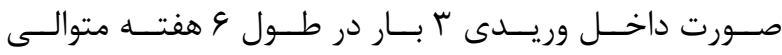

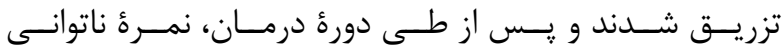

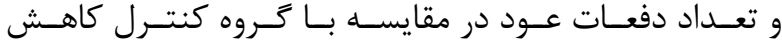

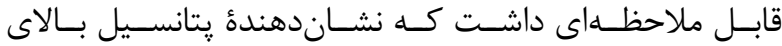

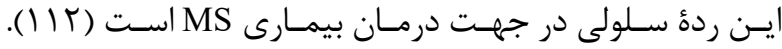

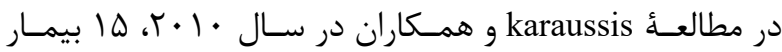

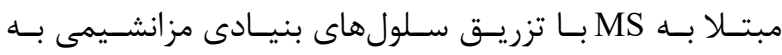

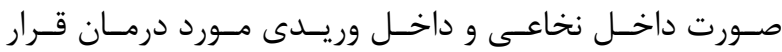

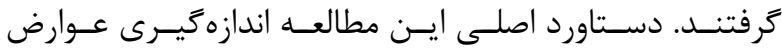

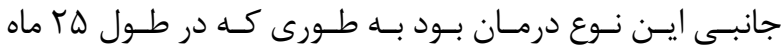

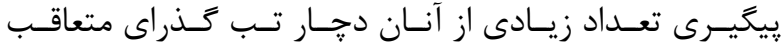

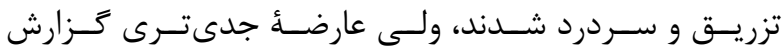

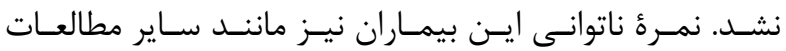

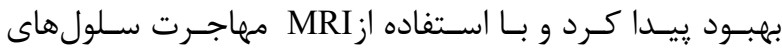

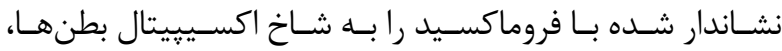

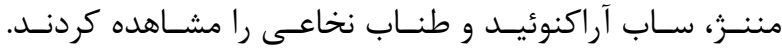

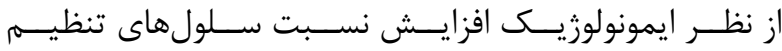

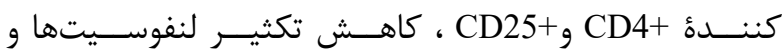

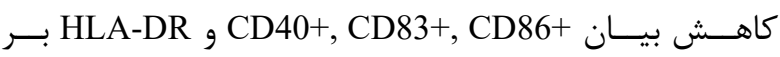

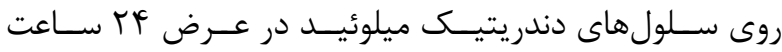

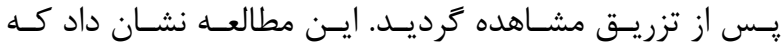

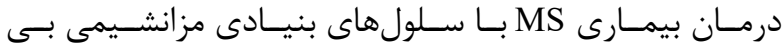

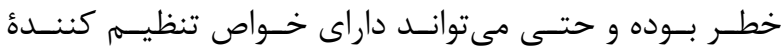

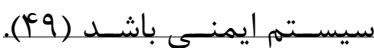

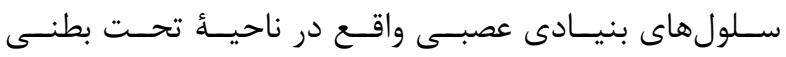

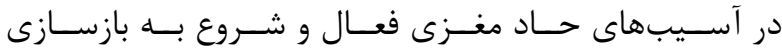

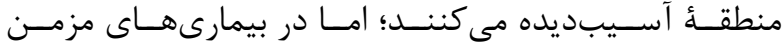

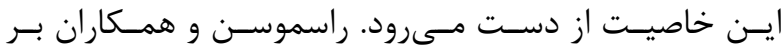

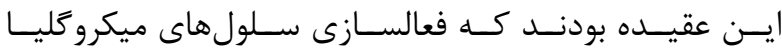

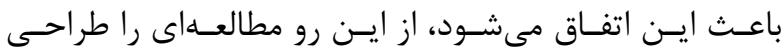

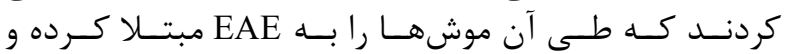

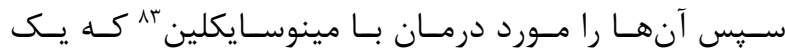

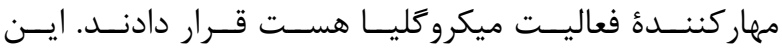

\begin{tabular}{|c|c|c|c|c|}
\hline 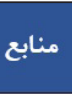 & نوع سلول بنيادى & $\begin{array}{l}\text { تعداد بيماران در } \\
\text { مطالعه }\end{array}$ & 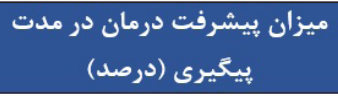 & 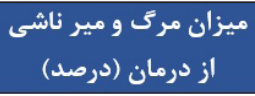 \\
\hline (IIf) & سلول بنيادى خونساز & re & 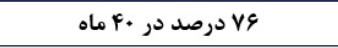 & $r / \Lambda$ \\
\hline (11Q) & سلول بنيادى خونساز & rI & Tצ كرصد در TF ماه & $9 / \Delta$ \\
\hline (119) & سلول بنيادى خونساز & IVA & • • درصد در •4 ماه & $\Delta / r$ \\
\hline (IIV) & سلول بنيادى خونساز & $r$ & ل V درصد در ب ماه & $9 / \Delta$ \\
\hline (IIA) & سلول بنيادى خونساز & rr & ك & $\cdot$ \\
\hline (119) & سلول بنيادى خونساز & rI & 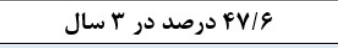 & $V / \Delta$ \\
\hline$(1.9)$ & سلول بنيادى خونساز & rI & 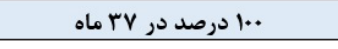 & $\cdot$ \\
\hline
\end{tabular}

${ }^{82}$ Human umbilical cord-derived mesenchymal stem cell

${ }^{83}$ Monocrystalline 


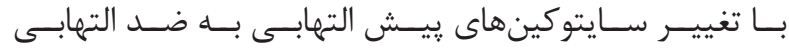

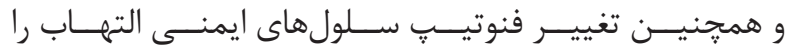

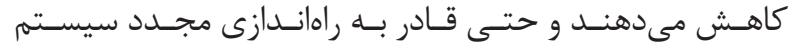

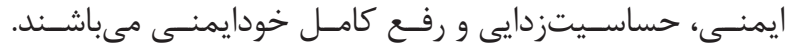

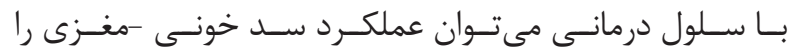

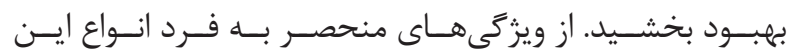

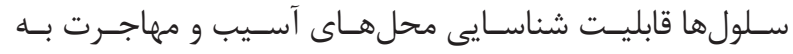

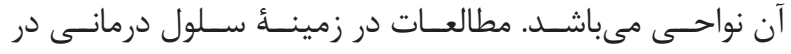

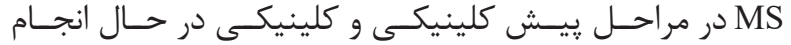

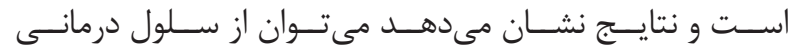

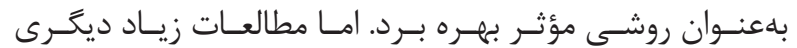

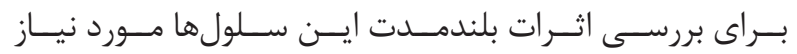

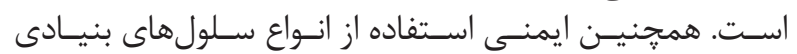

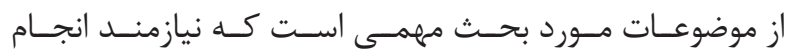

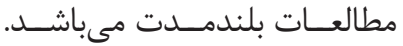

1. Siffrin V, Vogt J, Radbruch H, Nitsch R, Zipp F. Multiple sclerosis-candidate mechanisms underlying CNS atrophy. Trends Neurosci. 2010; 33(4): 202-10.

2. Gale CR, Martyn CN. Migrant studies in multiple sclerosis. Prog Neurobiol. 1995; 47(4): 425-48.

3. Muraro P, Leist T, Bielekova B, McFarland H. VLA4/CD49d downregulated on primed $T$ lymphocytes during interferon- $\beta$ therapy in multiple sclerosis. J Neuroimmunol. 2000; 111(1): 186-94.

4. Metz I, Weigand SD, Popescu BF, Frischer JM, Parisi JE, Guo Y, et al. Pathologic heterogeneity persists in early active multiple sclerosis lesions. Ann Neurol. 2014; 75(5): 728-38.

5. Li Y, Chu N, Hu A, Gran B, Rostami A, Zhang G-X. Increased IL-23p19 expression in multiple sclerosis lesions and its induction in microglia. Brain. 2006; 130(2): 490-501.

6. Akassoglou K, Bauer J, Kassiotis G, Pasparakis M, Lassmann H, Kollias G, et al. Oligodendrocyte apoptosis and primary demyelination induced by local $\mathrm{TNF} / \mathrm{p} 55 \mathrm{TNF}$ receptor signaling in the central nervous system of transgenic mice: models for multiple sclerosis with primary oligodendrogliopathy. Am J Pathol. 1998; 153(3): 801-13.

7. Bitsch A, Schuchardt J, Bunkowski S, Kuhlmann $\mathrm{T}$, Brück W. Acute axonal injury in multiple sclerosis: correlation with demyelination and inflammation. Brain. 2000; 123(6): 1174-83.

8. Harbison S. Cell therapy for multiple sclerosis: a new hope. Bioscience Horizons. 2014; 7: 1-11.
نتيجه

هيـج كـدام از درمانهـاى رايـج در بيمـارى MS كـهـ غالبـاً دارو

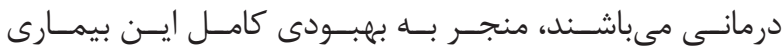

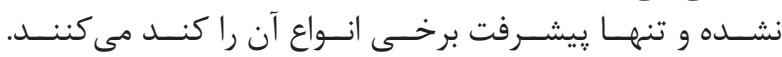

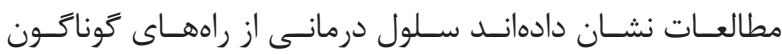

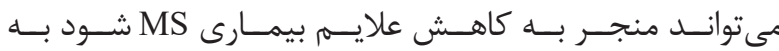

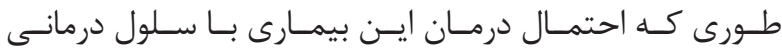

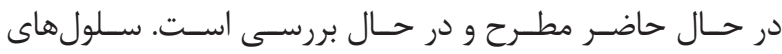

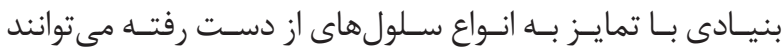

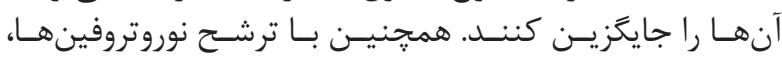

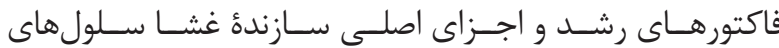

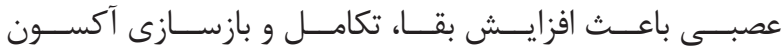

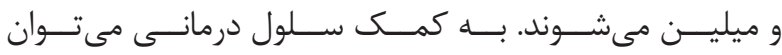

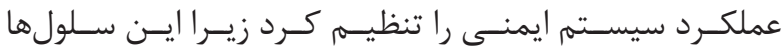

$$
\text { منابع }
$$

9. Liu Z, Pelfrey CM, Cotleur A, Lee J-C, Rudick RA. Immunomodulatory effects of interferon beta-1a in multiple sclerosis. J Neuroimmunol. 2001; 112(1): 153-62.

10. Guo B, Chang EY, Cheng G. The type I IFN induction pathway constrains Th17-mediated autoimmune inflammation in mice. J Clin Invest. 2008; 118(5): 1680-90.

11. Ramgolam VS, Sha Y, Jin J, Zhang X, MarkovicPlese S. IFN- $\beta$ inhibits human Th17 cell differentiation. J Immunol. 2009; 183(8): 5418-27.

12. Fridkis-Hareli M, Teitelbaum D, Gurevich E, Pecht I, Brautbar C, Kwon OJ, et al. Direct binding of myelin basic protein and synthetic copolymer 1 to class II major histocompatibility complex molecules on living antigenpresenting cells--specificity and promiscuity. Proc Natl Acad Sci U S A. 1994; 91(11): 4872-6.

13. Gran B, Tranquill L, Chen M, Bielekova B, Zhou W, Dhib-Jalbut S, et al. Mechanisms of immunomodulation by glatiramer acetate. Neurology. 2000; 55(11): 1704-14.

14. Johnson KP, Brooks BR, Cohen JA, Ford CC, Goldstein J, Lisak RP, et al. Extended use of glatiramer acetate (Copaxone) is well tolerated and maintains its clinical effect on multiple sclerosis relapse rate and degree of disability. Copolymer 1 Multiple Sclerosis Study Group. Neurology. 1998; 50(3): 701-8.

15. Wolinsky JS, Narayana PA, O’Connor P, Coyle PK, Ford C, Johnson K, et al. Glatiramer acetate in primary progressive multiple sclerosis: Results of a multinational, multicenter, double-blind, placebo-controlled trial. Ann Neurol. 2007; 61(1): 14-24. 


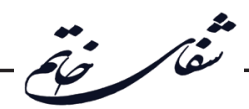

16. Polman CH, O’connor PW, Havrdova E, Hutchinson M, Kappos L, Miller DH, et al. A randomized, placebocontrolled trial of natalizumab for relapsing multiple sclerosis. N Engl J Med. 2006; 354(9): 899-910.

17. Hirsch HH, Kardas P, Kranz D, Leboeuf C. The human JC polyomavirus (JCPyV): virological background and clinical implications. Apmis. 2013; 121(8): $\quad 685-727$.

18. Matloubian M, Lo CG, Cinamon G, Lesneski MJ, $\mathrm{Xu} \mathrm{Y}$, Brinkmann $\mathrm{V}$, et al. Lymphocyte egress from thymus and peripheral lymphoid organs is dependent on S1P receptor 1. Nature. 2004; 427(6972): 355-60.

19. Brinkmann V, Billich A, Baumruker T, Heining P, Schmouder R, Francis G, et al. Fingolimod (FTY720): discovery and development of an oral drug to treat multiple sclerosis. Nat Rev Drug Discov. 2010; 9(11): 883-97.

20. Coles AJ, Cox A, Le Page E, Jones J, Trip SA, Deans J, et al. The window of therapeutic opportunity in multiple sclerosis. J Neurol. 2006; 253(1): 98-108.

21. Bourdette D, Yadav V. Alemtuzumab versus interferon beta-1a in early multiple sclerosis. $\mathrm{N}$ Engl $\mathrm{J}$ Med. 2009; 9(5): 341-2.

22. De Coppi P, Bartsch G, Siddiqui MM, Xu T, Santos $\mathrm{CC}$, Perin L, et al. Isolation of amniotic stem cell lines with potential for therapy. Nat Biotechnol. 2007; 25(1): 100-6.

23. Clewes O, Sieber-Blum M. Epidermal neural crest stem cells. neural crest stem cells. Breakthroughs and Applications. 2012; 109.

24. Hu YF, Zhang ZJ, Sieber-Blum M. An Epidermal neural crest stem cell (epi-ncsc) molecular signature. Stem Cells. 2006; 24(12): 2692-702.

25. Nieuwenhuys R, Puelles L. From neural plate to neural tube. Towards a New Neuromorphology. 2016. p. 44-8.

26. Nobakht M, Najafzadeh N, Safari M, Rahbar Roshandel N, Delaviz H, Joghataie MT, et al. 4.Bulge cells of rat hair follicles: isolation, cultivation, morphological and biological features. Yakhteh. 2010; 12(1): $51-8$

27. Tomokiyo A, Hynes $\mathrm{K}$, Gronthos S, Wada N, Bartold PM. Is there a role for neural crest stem cells in periodontal regeneration? Current Oral Health Reports. 2015; 2(4): 275-81.

28. Sakaue M, Sieber-Blum M. Human epidermal neural crest stem cells as a source of Schwann cells. Development. 2015; 142(18): 3188-97.

29. Spalding KL, Bergmann O, Alkass K, Bernard S, Salehpour M, Huttner HB, et al. Dynamics of hippocampal neurogenesis in adult humans. Cell. 2013; 153(6): 1219-27.

30. Preston M, Sherman LS. Neural stem cell niches: critical roles for the hyaluronan-based extracellular matrix in neural stem cell proliferation and differentiation. Front Biosci (Schol Ed). 2011; 3: 1165-79.

31. Gattazzo F, Urciuolo A, Bonaldo P. Extracellular matrix: a dynamic microenvironment for stem cell niche. Biochim Biophys Acta. 2014; 1840(8): 2506-19.

32. Gage FH. Mammalian neural stem cells. Science. 2000; 287(5457): 1433-8.

33. Baghishani F, Sahab Negah S. The role of neurogenesis in anxiety disorders. Shefaye Khatam. 2017; 5(2): 98-109.

34. Sahab Negah S, Eshaghabadi A, Mohammadzadeh E. The neuroprotective role of progesterone in traumatic brain injury; reduction of inflammatory cytokines. Shefaye Khatam. 2015; 3(4): 139-50.

35. Sahab Negah S, Mohammad Sadeghi S, Kazemi H, Modarres Mousavi M, Aligholi H. Effect of injured brain extract on proliferation of neural stem cells cultured in 3-dimensional environment. Shefaye Khatam. 2015; 3(1): 49-56.

36. Pasand Mozhdeh H, Zeynali B, Aligholi H, Kashani Radgerdi I, Sahab Negah S, Hassanzadeh G. The effect of intracerebroventricular administration of streptozocin on cell proliferation in subventricular zone stem cells in a rat model of alzheimer's disease. Shefaye Khatam. 2015; 3(4): 80-6.

37. Jahanbazi Jahan-Abad A, Morteza-zadeh P, Sahab Negah S, Gorji A. Curcumin attenuates harmful effects of arsenic on neural stem/progenitor cells. Avicenna J Phytomed. 2017; 7(4): 376-88.

38. Harris VK, Faroqui R, Vyshkina T, Sadiq SA. Characterization of autologous mesenchymal stem cellderived neural progenitors as a feasible source of stem cells for central nervous system applications in multiple sclerosis. Stem Cells Transl Med. 2012; 1(7): 536-47.

39. Mohammad Sadeghi S, Sahab Negah S, Khaksar Z, Kazemi H, Aligholi H. Laminin position as one of the important components of the extracellular matrix in tissue engineering of nervous system. Shefaye Khatam. 2014; 2(1): 69-74. 
40. Khaksar Z, Sahab Negah S, Mohammad Sadeghi S. Effects of a self-assembling peptide nanofiber containing laminin motif on survival and proliferation of embryonic rat neural stem cells. Shefaye Khatam. 2016; 4(2): 55-64.

41. Jahanbazi Jahan-Abad A, Morteza Zadeh P, Mohammadzadeh E, Khaksar Z, Mohammad Sadeghi S, Sahab Negah S. Proliferation assay of astrocytes isolated from rat neocortex in a nanopeptide scaffold. Shefaye Khatam. 2016; 4(4): 19-25.

42. Sahab Negah S, Khaksar Z, Aligholi H, Sadeghi SM, Mousavi SMM, Kazemi H, et al. Enhancement of neural stem cell survival, proliferation, migration, and differentiation in a novel self-assembly peptide nanofibber scaffold. Mol Neurobiol. 2017: 54(10): 8050-62.

43. Sahab Negah S, Aligholi H, Khaksar Z, Kazemi H, Mousavi SMM, Safahani M, et al. Survival, proliferation, and migration of human meningioma stem-like cells in a nanopeptide scaffold. Iranian Journal of Basic Medical Sciences. 2016; 19(12): 1271.

44. Vizoso FJ, Eiro N, Cid S, Schneider J, PerezFernandez R. Mesenchymal stem cell secretome: toward cell-free therapeutic strategies in regenerative medicine. Int J Mol Sci. 2017; 18(9): 1852. doi: 10.3390/ ijms 18091852 .

45. Srivatanakul P. Mesenchymal stem cells. Bangkok Medical Journal. 2013; 6: 71-9.

46. Ribeiro A, Laranjeira P, Mendes S, Velada I, Leite $\mathrm{C}$, Andrade $\mathrm{P}$, et al. Mesenchymal stem cells from umbilical cord matrix, adipose tissue and bone marrow exhibit different capability to suppress peripheral blood B, natural killer and T cells. Stem Cell Res Ther. 2013; 4(5): 125. doi: 10.1186/scrt336.

47. Bonab MM, Yazdanbakhsh S, Lotfi J, Alimoghaddom K, Talebian F, Hooshmand F, et al. Does mesenchymal stem cell therapy help multiple sclerosis patients? Report of a pilot study. Iran J Immunol. 2007; 4(1): 50-7.

48. Karussis D, Kassis I, Kurkalli BGS, Slavin S. Immunomodulation and neuroprotection with mesenchymal bone marrow stem cells (MSCs): a proposed treatment for multiple sclerosis and other neuroimmunological/neurodegenerative diseases. J Neurol Sci. 2008; 265(1): 131-5.

49. Karussis D, Karageorgiou C, Vaknin-Dembinsky A, Gowda-Kurkalli B, Gomori JM, Kassis I, et al. Safety and immunological effects of mesenchymal stem cell transplantation in patients with multiple sclerosis and amyotrophic lateral sclerosis. Arch Neurol. 2010; 67(10): 1187-94.

50. Uccelli A, Pistoia V, Moretta L. Mesenchymal stem cells: a new strategy for immunosuppression? Trends Immunol. 2007; 28(5): 219-6.

51. Uccelli A, Laroni A, Freedman MS. Mesenchymal stem cells for the treatment of multiple sclerosis and other neurological diseases. Lancet Neurol. 2011; 10(7): 649-56.

52. Ghaemi A, Abraki SB, Ghasemi S, Sajadian A, Togha M. Immunomodulatory role of mesenchymal stem cells against Multiple Sclerosis. Shefaye Khatam. 2014; 2(4): 60-70.

53. Pati S, Khakoo AY, Zhao J, Jimenez F, Gerber MH, Harting M, et al. Human mesenchymal stem cells inhibit vascular permeability by modulating vascular endothelial cadherin/ $\beta$-catenin signaling. Stem Cells Dev. 2010; 20(1): 89-101.

54. Walker PA, Shah SK, Jimenez F, Gerber MH, Xue $\mathrm{H}$, Cutrone $\mathrm{R}$, et al. Intravenous multipotent adult progenitor cell therapy for traumatic brain injury: preserving the blood brain barrier via an interaction with splenocytes. Exp Neurol. 2010; 225(2): 341-52.

55. Pati S, Gerber MH, Menge TD, Wataha KA, Zhao Y, Baumgartner JA, et al. Bone marrow derived mesenchymal stem cells inhibit inflammation and preserve vascular endothelial integrity in the lungs after hemorrhagic shock. Plos One. 2011; 6(9): e25171.

56. Bai L, Lennon DP, Caplan AI, DeChant A, Hecker J, Kranso J, et al. Hepatocyte growth factor mediates mesenchymal stem cell-induced recovery in multiple sclerosis models. Nat Neurosci. 2012; 15(6): 862-70.

57. Lutz SE, Lengfeld J, Agalliu D. Stem cell-based therapies for multiple sclerosis: recent advances in animal models and human clinical trials. R Regen Med. 2014; 9(2): 129-32.

58. Hof Wvt, Mal N, Raber A, Zhang M, Ting A, Deans R. Multipotent adult progenitor cells. Stem Cells and Myocardial Regeneration. 2007: 45-56.

59. Olson JK, Miller SD. Microglia initiate central nervous system innate and adaptive immune responses through multiple TLRs. J Immunol. 2004; 173(6): 3916-24.

60. Smith HS. Activated microglia in nociception. Pain Physician. 2009; 13(3): 295-304.

61. Walker PA, Bedi SS, Shah SK, Jimenez F, Xue 
H, Hamilton JA, et al. Intravenous multipotent adult progenitor cell therapy after traumatic brain injury: modulation of the resident microglia population. J Neuroinflammation. 2012; 9: 228. doi: 10.1186/17422094-9-228.

62. Tabakow P, Jarmundowicz W, Czapiga B, Fortuna W, Miedzybrodzki R, Czyz M, et al. Transplantation of autologous olfactory ensheathing cells in complete human spinal cord injury. Cell Transplant. 2013; 22(9): 1591-612.

63. Feron F, Perry C, Cochrane J, Licina P, Nowitzke A, Urquhart S, et al. Autologous olfactory ensheathing cell transplantation in human spinal cord injury. Brain. 2005; 128(12): 2951-60.

64. Wang S, Bates J, Li X, Schanz S, Chandler-Militello D, Levine C, et al. Human iPSC-derived oligodendrocyte progenitor cells can myelinate and rescue a mouse model of congenital hypomyelination. Cell Stem Cell. 2013; 12(2): 252-64.

65. Roet KC, Verhaagen J. Understanding the neural repair-promoting properties of olfactory ensheathing cells. Exp Neurol. 2014; 261: 594-609.

66. Li J, Chen W, Li Ya, Chen Y, Ding Z, Yang D, et al. Transplantation of olfactory ensheathing cells promotes partial recovery in rats with experimental autoimmune encephalomyelitis. Int J Clin Exp Pathol. 2015; 8(9): 11149-56.

67. Grant MB, May WS, Caballero S, Brown GA, Guthrie SM, Mames RN, et al. Adult hematopoietic stem cells provide functional hemangioblast activity during retinal neovascularization. Nat Med. 2002; 8(6): 607-12.

68. Shevchenko JL, Kuznetsov AN, Ionova TI, Melnichenko VY, Fedorenko DA, Kartashov AV, et al. Autologous hematopoietic stem cell transplantation with reduced-intensity conditioning in multiple sclerosis. Exp Hematol. 2012; 40(11): 892-8.

69. Alexander T, Arnold R, Hiepe F, Radbruch A. Resetting the immune system with immunoablation and autologous haematopoietic stem cell transplantation in autoimmune diseases. Clin Exp Rheumatol. 2016; 34(4): $53-S 7$.

70. Alessandra de Paula AS, Malmegrim KC, Panepucci RA, Brum DS, Barreira AA, Dos Santos AC, et al. Autologous haematopoietic stem cell transplantation reduces abnormalities in the expression of immune genes in multiple sclerosis. Clin Sci (Lond). 2015; 128(2): 111-20

71. Chung J-Y, Figgett W, Fairfax K, Bernard C, Chan $\mathrm{J}$, Toh B-H, et al. Gene therapy delivery of myelin oligodendrocyte glycoprotein (MOG) via hematopoietic stem cell transfer induces MOG-specific B cell deletion. J Immunol. 2014; 192(6): 2593-601.

72. Simonsen CS, Hansen G, Piehl F, Edland A. Chronic inflammatory demyelinating polyradiculoneuropathy occurring after autologous haematopoietic stem cell transplantation for multiple sclerosis. Mult Scler J Exp Transl Clin. 2016; 2: doi: 10.1177/2055217316658304.

73. Abrahamsson SV, Angelini DF, Dubinsky AN, Morel E, Oh U, Jones JL, et al. Non-myeloablative autologous haematopoietic stem cell transplantation expands regulatory cells and depletes IL-17 producing mucosalassociated invariant $\mathrm{T}$ cells in multiple sclerosis. Brain. 2013; 136(9): 2888-903.

74. Kondo T, Raff M. Oligodendrocyte precursor cells reprogrammed to become multipotential CNS stem cells. Science. 2000; 289(5485): 1754-7.

75. Noll E, Miller RH. Oligodendrocyte precursors originate at the ventral ventricular zone dorsal to the ventral midline region in the embryonic rat spinal cord. Development. 1993;118(2): 563-73.

76. Ben-Hur T, Einstein O, Mizrachi-Kol R, BenMenachem O, Reinhartz E, Karussis D, et al. Transplanted multipotential neural precursor cells migrate into the inflamed white matter in response to experimental autoimmune encephalomyelitis. Glia. 2003; 41(1): 73-80.

77. Wolswijk G. Oligodendrocyte precursor cells in the demyelinated multiple sclerosis spinal cord. Brain. 2002; 125(2): 338-49.

78. Greenberg ML, Weinger JG, Matheu MP, Carbajal KS, Parker I, Macklin WB, et al. Two-photon imaging of remyelination of spinal cord axons by engrafted neural precursor cells in a viral model of multiple sclerosis. Proc Natl Acad Sci U S A. 2014; 111(22): E2349-E55.

79. Milner R, Anderson HJ, Rippon RF, McKay JS, Franklin RJ, Marchionni MA, et al. Contrasting effects of mitogenic growth factors on oligodendrocyte precursor cell migration. Glia. 1997; 19(1): 85-90.

80. Murohara T, Ikeda H, Duan J, Shintani S, Sasaki $\mathrm{K}-\mathrm{i}$, Eguchi $\mathrm{H}$, et al. Transplanted cord bloodderived endothelial precursor cells augment postnatal neovascularization. J Clin Invest. 2000; 105(11): 1527-36.

81. Bogoslovsky T, Chaudhry A, Latour L, Maric D, Luby M, Spatz M, et al. Endothelial progenitor cells correlate with lesion volume and growth in acute stroke. Neurology. 2010; 75(23): 2059-62.

82. Kaneko Y, Tajiri N, Shinozuka K, E Glover L, L Weinbren N, Cortes L, et al. Cell therapy for stroke: 
emphasis on optimizing safety and efficacy profile of endothelial progenitor cells. Curr Pharm Des. 2012; 18(25): 3731-4.

83. Bogoslovsky T, Spatz M, Chaudhry A, Maric D, Luby M, Frank J, et al. Circulating CD133+ CD34+ progenitor cells inversely correlate with soluble ICAM1 in early ischemic stroke patients. J Transl Med. 2011; 9(1): 145. doi: 10.1186/1479-5876-9-145.

84. Paczkowska E, Gołąb-Janowska M, BajerCzajkowska A, Machalińska A, Ustianowski P, Rybicka $\mathrm{M}$, et al. Increased circulating endothelial progenitor cells in patients with haemorrhagic and ischaemic stroke: the role of endothelin-1. J Neurol Sci. 2013; 325(1): 90-9.

85. Navarro-Sobrino M, Hernández-Guillamon $M$, Fernandez-Cadenas I, Ribó M, Romero IA, Couraud $\mathrm{P}-\mathrm{O}$, et al. The angiogenic gene profile of circulating endothelial progenitor cells from ischemic stroke patients. Vasc Cell. 2013; 5(1): 3. doi: 10.1186/2045824X-5-3.

86. Shen Q, Goderie SK, Jin L, Karanth N, Sun Y, Abramova N, et al. Endothelial cells stimulate selfrenewal and expand neurogenesis of neural stem cells. Science. 2004; 304(5675): 1338-40.

87. Placone AL, Quiñones-Hinojosa A, Searson PC. The role of astrocytes in the progression of brain cancer: complicating the picture of the tumor microenvironment. Tumour Biol. 2016; 37(1): 61-9.

88. Aggarwal S, Pittenger MF. Human mesenchymal stem cells modulate allogeneic immune cell responses. Blood. 2005; 105(4): 1815-22.

89. Rivera FJ, Couillard-Despres S, Pedre X, Ploetz S, Caioni M, Lois C, et al. Mesenchymal stem cells instruct oligodendrogenic fate decision on adult neural stem cells. Stem Cells. 2006; 24(10): 2209-19.

90. Lindvall O, Kokaia Z. Prospects of stem cell therapy for replacing dopamine neurons in Parkinson's disease. Trends Pharmacol Sci. 2009; 30(5): 260-7.

91. Nori S, Okada Y, Yasuda A, Tsuji O, Takahashi Y, Kobayashi Y, et al. Grafted human-induced pluripotent stem-cell-derived neurospheres promote motor functional recovery after spinal cord injury in mice. Proc Natl Acad Sci U S A. 2011; 108(40): 16825-30.

92. Bai L, Hecker J, Kerstetter A, Miller RH. Myelin repair and functional recovery mediated by neural cell transplantation in a mouse model of multiple sclerosis. Neurosci Bull. 2013; 29(2): 239-50.

93. Lu P, Jones L, Snyder E, Tuszynski M. Neural stem cells constitutively secrete neurotrophic factors and promote extensive host axonal growth after spinal cord injury. Exp Neurol. 2003; 181(2): 115-29.

94. Sieber-Blum M. Neural crest stem cells: breakthroughs and applications: World Scientific. Newcastle University, UK. 2012. p. 168.

95. Espinosa de los Monteros A, Zhao P, Huang C, Pan T, Chang R, Nazarian R, et al. Transplantation of CG4 oligodendrocyte progenitor cells in the myelin-deficient rat brain results in myelination of axons and enhanced oligodendroglial markers. J Neurosci Res. 1997; 50(5): 872-87.

96. Akiyama Y RC, Kocsis JD. Remyelination of rat spinal cord by implantation of identified bone marrow stromal cells. J Neurosci. 2002; 22(15): 6623-30.

97. Copray S, Balasubramaniyan V, Levenga J, de Bruijn J, Liem R, Boddeke E. Olig2 overexpression induces the in vitro differentiation of neural stem cells into mature oligodendrocytes. Stem Cells. 2006; 24(4): 1001-10.

98. Zhang C, Cao J, Li X, Xu H, Wang W, Wang L, et al. Treatment of multiple sclerosis by transplantation of neural stem cells derived from induced pluripotent stem cells. Sci China Life Sci. 2016; 59(9): 950-7.

99. Yandava BD, Billinghurst LL, Snyder EY. "Global" cell replacement is feasible via neural stem cell transplantation: evidence from the dysmyelinated shiverer mouse brain. Proc Natl Acad Sci U S A. 1999; 96(12): 7029-34.

100. Liu S, Qu Y, Stewart TJ, Howard MJ, Chakrabortty S, Holekamp TF, et al. Embryonic stem cells differentiate into oligodendrocytes and myelinate in culture and after spinal cord transplantation. Proc Natl Acad Sci U S A. 2000; 97(11): 6126-31.

101. Glaser T, Perez-Bouza A, Klein K, Brüstle O. Generation of purified oligodendrocyte progenitors from embryonic stem cells. FASEB J. 2005; 19(1): 112-4.

102. Windrem MS, Nunes MC, Rashbaum WK, Schwartz TH, Goodman RA, McKhann G, et al. Fetal and adult human oligodendrocyte progenitor cell isolates myelinate the congenitally dysmyelinated brain. Nat Med. 2004; 10(1): 93-7.

103. Keirstead HS, Nistor G, Bernal G, Totoiu M, Cloutier F, Sharp K, et al. Human embryonic stem cellderived oligodendrocyte progenitor cell transplants remyelinate and restore locomotion after spinal cord injury. J Neurosci. 2005; 25(19): 4694-705.

104. Karussis D, Petrou P, Kassis I. Clinical experience with stem cells and other cell therapies in 


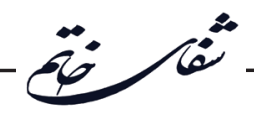

neurological diseases. J Neurol Sci 2013; 324(1-2): 1-9.

105. Connick P, Kolappan M, Crawley C, Webber DJ, Patani R, Michell AW, et al. Autologous mesenchymal stem cells for the treatment of secondary progressive multiple sclerosis: an open-label phase 2 a proof-ofconcept study. Lancet Neurol. 2012; 11(2): 150-6.

106. Mancardi GL, Sormani MP, Di Gioia M, Vuolo L, Gualandi F, Amato MP, et al. Autologous haematopoietic stem cell transplantation with an intermediate intensity conditioning regimen in multiple sclerosis: the Italian multi-centre experience. Mult Scler. 2012; 18(6): 835-42.

107. Saccardi R, Mancardi GL, Solari A, Bosi A, Bruzzi P, Di Bartolomeo P, et al. Autologous HSCT for severe progressive multiple sclerosis in a multicenter trial: impact on disease activity and quality of life. Blood. 2005; 105(6): 2601-7.

108. Nash RA, Hutton GJ, Racke MK, Popat U, Devine SM, Griffith LM, et al. High-dose immunosuppressive therapy and autologous hematopoietic cell transplantation for relapsing-remitting multiple sclerosis (HALT-MS): a 3-year interim report. JAMA Neurol. 2015; 72(2): 159-69.

109. Harris VK, Vyshkina T, Sadiq SA. Clinical safety of intrathecal administration of mesenchymal stromal cell-derived neural progenitors in multiple sclerosis. Cytotherapy. 2016; 18(12): 1476-82.

110. Stepien A, Dabrowska NL, Maciagowska M, Macoch RP, Zolocinska A, Mazur S, et al. Clinical application of autologous adipose stem cells in patients with multiple sclerosis: preliminary results. Mediators Inflamm. 2016; 2016.

111. Mohyeddin Bonab M, Ali Sahraian M, Aghsaie A, Ahmadi Karvigh S, Massoud Hosseinian S, Nikbin B, et al. Autologous mesenchymal stem cell therapy in progressive multiple sclerosis: an open label study. C Curr Stem Cell Res Ther. 2012; 7(6): 407-14.

112. Li J-F, Zhang D-J, Geng T, Chen L, Huang H, Yin H-L, et al. The potential of human umbilical cord- derived mesenchymal stem cells as a novel cellular therapy for multiple sclerosis. Cell Transplant. 2014; 23(1): S113-S22.

113. Rasmussen S, Imitola J, Ayuso-Sacido A, Wang Y, Starossom SC, Kivisäkk P, et al. Reversible neural stem cell niche dysfunction in a model of multiple sclerosis. Ann Neurol. 2011; 69(5): 878-91.

114. Nash RA, Bowen JD, McSweeney PA, Pavletic SZ, Maravilla KR, Park M-s, et al. High-dose immunosuppressive therapy and autologous peripheral blood stem cell transplantation for severe multiple sclerosis. Blood. 2003; 102(7): 2364-72.

115. Burt RK, Cohen BA, Russell E, Spero K, Joshi A, Oyama Y, et al. Hematopoietic stem cell transplantation for progressive multiple sclerosis: failure of a total body irradiation-based conditioning regimen to prevent disease progression in patients with high disability scores. Blood. 2003; 102(7): 2373-8.

116. Saccardi R, Kozak T, Bocelli-Tyndall C, Fassas A, Kazis A, Havrdova E, et al. Autologous stem cell transplantation for progressive multiple sclerosis: update of the european group for blood and marrow transplantation autoimmune diseases working party database. Mult Scler. 2006; 12(6): 814-23.

117. Ni XS, Ouyang J, Zhu WH, Wang C, Chen B. Autologous hematopoietic stem cell transplantation for progressive multiple sclerosis: report of efficacy and safety at three yr of follow up in 21 patients. Clin Transplant. 2006; 20(4): 485-9.

118. Krasulová E, Trněný M, Kozák T, Vacková B, Pohlreich D, Kemlink D, et al. High-dose immunoablation with autologous haematopoietic stem cell transplantation in aggressive multiple sclerosis: a single centre 10-year experience. Mult Scler. 2010; 16(6): 685-93.

119. Hamerschlak N, Rodrigues M, Moraes D, Oliveira M, Stracieri A, Pieroni F, et al. Brazilian experience with two conditioning regimens in patients with multiple sclerosis: BEAM/horse ATG and CY/rabbit ATG. Bone Marrow Transplant. 2010; 45(2): 239-48. 